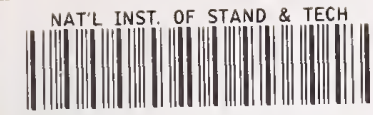

Al」lU6 334960

NBS Special Publication 673

NBS

JBLICATIONS

Economic Model of

Calibration Improvements

for Automatic Test Equipment

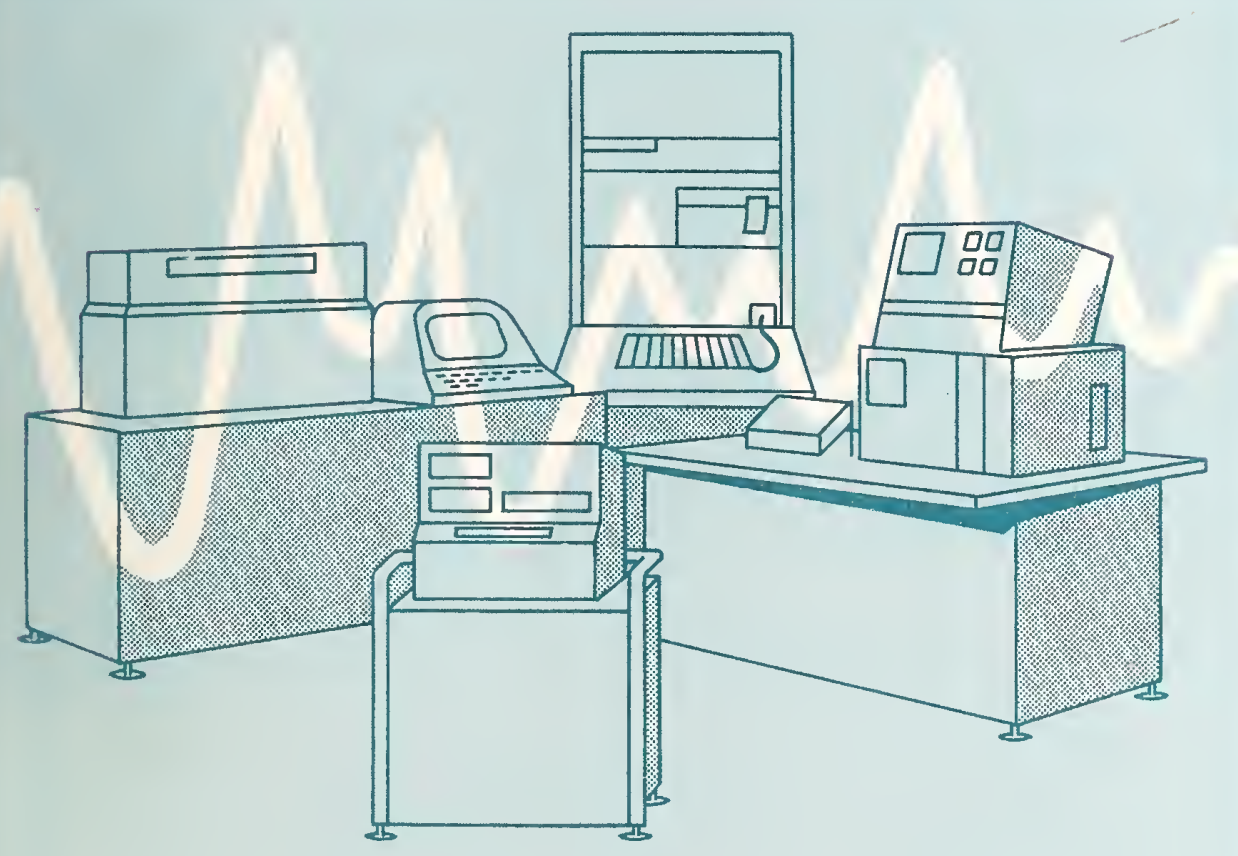

U.S. Department of Commerce

National Bureau of Standards

$O C$

100

.057

$\mathrm{No} 0.573$

$\frac{1934}{c} \cdot 2$ 


\section{NATIONAL BUREAU OF STANDARDS}

The Nationa! Bureau of Standards' was established by an act of Congress on March 3, 1901. The Bureau's overall goal is to strengthen and advance the Nation's science and technology and facilitate their effective application for public benelit. To this end, the Bureau conducts research and provides: (1) a basis for the Nation's physical measurement system, (2) scientific and technological services for industry and government, (3) a technical basis for equity in trade, and (4) technical services to promote public safety. The Bureau's technical work is performed by the National Measurement Laboratory, the National Engineering Laboratory, and the Institute for Computer Sciences and Technology.

THE NATIONAL MEASUREMENT LABORATORY provides the national system of physical and chemical and materials measurement; coordinates the system with measurement systems of other nations and furnishes essential services leading to accurate and uniform physical and chemical measurement throughout the Nation's scientific community, industry, and commerce; conducts materials research leading to improved methods of measurement, standards, and data on the properties of materials needed by industry, commerce, educational institutions, and Government; provides advisory and research services to other Government agencies; develops, produces, and distributes Standard Reference Materials; and provides calibration services. The Laboratory consists of the following centers:

\section{Absolute Physical Quantities ${ }^{2}$ - Radiation Research - Chemical Physics - Analytical Chemistry - Materials Science}

THE NATIONAL ENGINEERING LABORATORY provides technology and technical services to the public and private sectors to address national needs and to solve national problems; conducts research in engineering and applied science in support of these efforts; builds and maintains competence in the necessary disciplines required to carry out this research and technical service; develops engineering data and measurement capabilities; provides engineering measurement traceability services; develops test methods and proposes engineering standards and code changes; develops and proposes new engineering practices; and develops and improves mechanisms to transfer results of its research to the ultimate user. The Laboratory consists of the following centers:

Applied Mathematics - Electronics and Electrical Engineering ${ }^{2}$ - Manufacturing Engineering - Building Technology - Fire Research - Chemical Engineering ${ }^{2}$

THE INSTITUTE FOR COMPUTER SCIENCES AND TECHNOLOGY conducts research and provides scientific and technical services to aid Federal agencies in the selection, acquisition, application, and use of computer technology to improve effectiveness and economy in Government operations in accordance with Public Law 89-306 (40 U.S.C. 759), relevant Executive Orders, and other directives; carries out this mission by managing the Federal Information Processing Standards Program, developing Federal ADP standards guidelines, and managing Federal participation in ADP voluntary standardization activities; provides scientific and technological advisory services and assistance to Federal agencies; and provides the technical foundation for computer-related policies of the Federal Government. The Institute consists of the following centers:

Programming Science and Technology-Computer Systems Engineering.

'Headquarters and Laboratories at Gaithersburg, MD, unless olherwise noted;

mailing address Washington, DC 20234.

${ }^{2}$ Some divisions within the cenler are located at Boulder, CO 80303. 


\title{
Economic Model of Calibration Improvements for Automatic Test Equipment
}

\author{
Stephen F. Weber
}

Anne P. Hillstrom

Center for Applied Mathematics

National Engineering Laboratory

National Bureau of Standards

Washington, DC 20234

Sponsored by :

Center for Electronics and Electrical Engineering

Center for Applied Mathematics

National Bureau of Standards

Washington, DC 20234

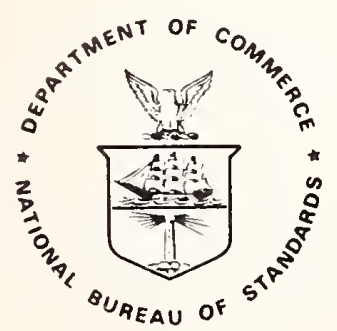

U.S. DEPARTMENT OF COMMERCE, Malcolm Baldrige, Secretary NATIONAL BUREAU OF STANDARDS, Ernest Ambler, Director

Issued April 1984 
Library of Congress Catalog Card Number: 84-601027

National Bureau of Standards Special Publication 673

Natl. Bur. Stand. (U.S.), Spec. Publ. 673, 94 pages (Apr. 1984) CODEN: XNBSAV 


\section{Abstract}

This paper presents a model for measuring the benefits of improved accuracy in test equipment. The model permits calculation of the probability of accepting a unit under test (UUT) that is out of specifications (1.e., Consumer's Loss) and the probability of rejecting a UUT that is within specifications (i.e., Producer's Loss) for alternative levels of test equipment accuracy. Accuracy is defined in terms of both the systematic and the random measurement error of the equipment. Other parameters that are taken into account by the model are the mean and variance of the UUT attribute of interest, the performance specifications of the UUT, and the test specifications which define acceptance and rejection in terms of test measurement results. A discussion of the economic consequences of Consumer's Loss and Producer's Loss is included. The model may be used to optimize both procurement policy for new test equipment as well as maintenance and calibration policy for existing test equipment.

Key words: accuracy; automatic test equipment; callbration; Consumer's Loss; economics; error analysis; measurement; Producer's Loss; quality assurance; random error; systematic error; testing. 



\section{Acknowledgements}

This research is jointly funded by the Center for Applied Mathematics (CAM) and the Center for Electronics and Electrical Engineering (CEEE), both of the National Bureau of Standards. The authors are grateful for the useful suggestions and guidance offered by a number of colleagues and reviewers. Those deserving special appreciation are Judson French and Ronald Powell of CEEE headquarters; Barry Be11, Paul Lederer, Thomas Leedy, and Oskars Petersons of the Electrosystems Division of CEEE; Janet Russell of CAM headquarters; James Filliben, James Lechner, Mary Natrella, and Charles Reeve of the Statistical Engineering Division of CAM; Javier Bernal, Robert Chapman, Jacqueline Kee, Laurene Linsenmayer, Barbara Lippiatt, Harold Marshall, and Rosemary Massengill of the Operations Research Division of CAM; George Dines of the Computer Services Division of CAM; James Barnett of the Building Physics Division of the Center for Building Technology; Donald Owen of Southern Methodist University; and Ingram 0lkin of Stanford University. 


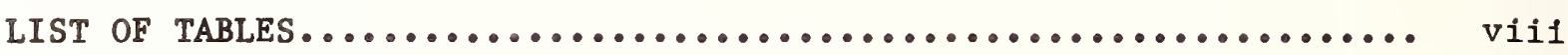

LIST OF FIGURES.................................... Ix

1. INTRODUCTION ...................................... 1

1.1. Background and objective......................... 1

1.2. scope....................................... 2

1.3. Organization................................. 5

2. MATHEMATICAL FORMULATION OF THE MODEL.................... 7

2.1. The Basic Mode1................................ 7

2.2. Extensions of the Mode1........................... 15

3. RESULTS.......................................... 19

3.1. Effects of Systematic Measurement Error................ 19

3.1.1. Direction of Effects....................... 19

3.1.2. Pattern and Magnitude of Effects............... 30

3.2. Effects of Random Measurement Error................... 37

3.2.1. Direction of Effects..................... 37

3.2.2. Pattern and Magnitude of Effects.............. 40

4. SUMMARY AND APPLICATION............................. 46

BIBLIOGRAPHY........................................ 48

APPENDIX A: BINORMAL.CL-PL, AN INTERACTIVE COMPUTER PROGRAM FOR CALCULATING CONSUMER'S LOSS AND PRODUCER'S LOSS IN TESTING..................................

A.1. Purpose............................... 51

A.2. scope................................ 52

A.3. Using the Program........................ 53

A.4. Program Characteristics.................... 56 
APPENDIX B: PLOTS OF CONSUMER'S LOSS AND PRODUCER'S LOSS AS FUNCTIONS OF THE MEAN AND STANDARD DEVIATION OF MEASUREMENT ERROR............................ 63

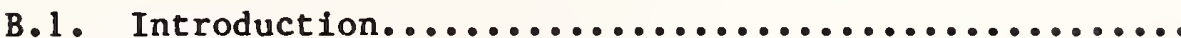
63

B.2. scope................................. 63

B.3. Interpretation of the Plots................... 65

B.4. Illustrative Applications of the Figures.......... 79 


\section{List of Tables}

Page

2.1 Notation Used in the Model and in Appendix B............... 8

3.1 Parameter Values and Systematic Error Values Used to

Analyze the Direction of the Effect of Systematic

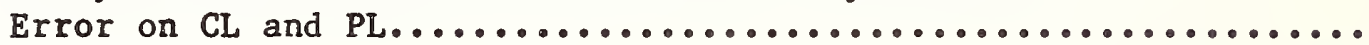

3.2 Critical Values of $T A / \sigma_{\varepsilon}$ Below Which CL Decreases With

Increasing Systematic Error, For Various Symmetric

Performance Limits and Standard Deviations of Measurement Error...

3.3 Parameter Values and Systematic Error Values Used to Analyze the Pattern and Magnitude of the Effect of Systematic Error on

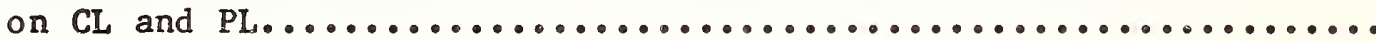

3.4 Parameter Values and Standard Deviation of Measurement Error Values Used to Analyze the Direction of the Effect of the

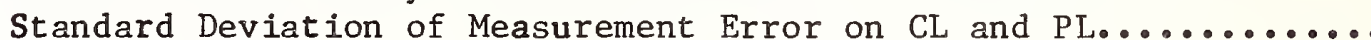

3.5 Parameter Values and Standard Deviation of Measurement Error Values Used to Analyze the Pattern and Magnitude of the Effect of the Standard Deviation of Measurement Error on CL and PL......

A.1 Input Variables for BINORMAL.CL-PL......................

B.1 Parameter Values and Resulting Values of CL and PL for Case Examples. 
3.1. Comparison of the Relative Cost Ratio, $\mathrm{C}_{\mathrm{CL}} / \mathrm{C}_{\mathrm{PL}}$, With the Absolute Value of the Relative Change Ratio, $\Delta \mathrm{PL} / \Delta \mathrm{CL}$, for a Performance Specification of One Standard Deviation........

3.2. Comparison of the Relative Cost Ratio, $\mathrm{C}_{\mathrm{CL}} / \mathrm{C}_{\mathrm{PL}}$, With the Absolute Value of the Relative Change Ratio, $\triangle \mathrm{PL} / \Delta \mathrm{CL}$, for a Performance Specification of Two Standard Deviations..........

3.3. Comparison of the Relative Cost Ratio, $\mathrm{C}_{\mathrm{CL}} / \mathrm{C}_{\mathrm{PL}}$, with the Absolute Value of the Relative Change Ratio, $\Delta \mathrm{PL} / \Delta \mathrm{CL}$, for a Performance Specification of Three Standard Deviations.........

3.4. Consumer's Loss as a Function of Systematic Measurement Error (Bias), for Characteristic Values of Test Tolerance.............

3.5. Producer's Loss as a Function of Systematic Measurement Error (Bias), for Characteristic Values of Test Tolerance.............

3.6. Consumer's Loss as a Function of Standard Deviation of Measurement Error, for Characteristic Values of Test Tolerance....

3.7. Producer's Loss as a Function of Standard Deviation of Measurement Error, for Characteristic Values of Test Tolerance....

A.1. Illustrative Computer Run of BINORMAL.CL-PL................ 55

A.2. Computer Code Listing of BINORMAL.CL-PL................. 58

B.1. Effect of Systematic Measurement Error on Consumer's Loss $\left(\sigma_{\varepsilon}=0.5, \mu_{\mathrm{u}}=0, \sigma_{\mathrm{u}}=1, \mathrm{~S}_{\mathrm{U}}=2, \mathrm{~S}_{\mathrm{L}}=-2\right) \ldots \ldots \ldots \ldots \ldots \ldots \ldots \ldots \ldots \ldots \ldots \ldots \ldots \ldots \ldots \ldots \ldots$

B.2. Effect of Systematic Measurement Error on Consumer's Loss $\left(\sigma_{\varepsilon}=0.25, \mu_{\mathrm{u}}=0, \sigma_{\mathrm{u}}=1, \mathrm{~s}_{\mathrm{U}}=2, \mathrm{~s}_{\mathrm{L}}=-2\right) \ldots \ldots \ldots \ldots \ldots \ldots \ldots \ldots \ldots \ldots \ldots \ldots \ldots \ldots \ldots \ldots \ldots \ldots \ldots$

B.3. Effect of Systematic Measurement Error on Consumer's Loss $\left(\sigma_{\varepsilon}=0.1, \mu_{\mathrm{u}}=0, \sigma_{\mathrm{u}}=1, \mathrm{~s}_{\mathrm{U}}=2, \mathrm{~s}_{\mathrm{L}}=-2\right) \ldots \ldots \ldots \ldots \ldots \ldots \ldots \ldots \ldots \ldots \ldots \ldots \ldots \ldots \ldots \ldots \ldots$

B.4. Effect of Systematic Measurement Error on Producer's Loss $\left(\sigma_{\varepsilon}=0.5, \mu_{u}=0, \sigma_{u}=1, S_{U}=2, S_{L}=-2\right)$.

B.5. Effect of Systematic Measurement Error on Producer's Loss $\left(\sigma_{\varepsilon}=0.25, \mu_{\mathrm{u}}=0, \sigma_{\mathrm{u}}=1, \mathrm{~S}_{\mathrm{U}}=2, \mathrm{~S}_{\mathrm{L}}=-2\right)$

B.6. Effect of Systematic Measurement Error on Producer's Loss $\left(\sigma_{\varepsilon}=0.1, \mu_{\mathrm{u}}=0, \sigma_{\mathrm{u}}=1, \mathrm{~S}_{\mathrm{U}}=2, \mathrm{~S}_{\mathrm{L}}=-2\right)$

B.7. Effect of Standard Deviation of Measurement Error on Consumer's Loss $\left(\mu_{\varepsilon}=0.5, \mu_{\mathrm{u}}=0, \sigma_{\mathrm{u}}=1, \mathrm{~s}_{\mathrm{U}}=2, \mathrm{~s}_{\mathrm{L}}=-2\right) \ldots \ldots \ldots \ldots \ldots \ldots \ldots \ldots \ldots \ldots \ldots \ldots \ldots \ldots \ldots$ 
B.8. Effect of Standard Deviation of Measurement Error on Consumer's Loss $\left(\mu_{\varepsilon}=0.25, \mu_{\mathrm{u}}=0, \sigma_{\mathrm{u}}=1, \mathrm{~S}_{\mathrm{U}}=2, \mathrm{~S}_{\mathrm{L}}=-2\right)$

B.9. Effect of Standard Deviation of Measurement Error on Consumer's Loss $\left(\mu_{\varepsilon}=0, \mu_{u}=0, \sigma_{u}=1, s_{U}=2, s_{L}=-2\right) \ldots \ldots \ldots \ldots \ldots \ldots \ldots \ldots \ldots$

B.10. Effect of Standard Deviation of Measurement Error on Producer's Loss $\left(\mu_{\varepsilon}=0.5, \mu_{u}=0, \sigma_{u}=1, S_{U}=2, s_{L}=-2\right) \ldots \ldots \ldots \ldots \ldots \ldots \ldots \ldots \ldots \ldots \ldots \ldots \ldots$

B.11. Effect of Standard Deviation of Measurement Error on Producer's Loss $\left(\mu_{\varepsilon}=0.25, \mu_{u}=0, \sigma_{u}=1, S_{U}=2, s_{L}=-2\right) \ldots \ldots \ldots \ldots \ldots \ldots \ldots \ldots \ldots \ldots \ldots$

B.12. Effect of Standard Deviation of Measurement Error on Producer's Loss $\left(\mu_{\varepsilon}=0, \mu_{u}=0, \sigma_{u}=1, S_{U}=2, S_{L}=-2\right)$ 


\section{Introduction}

\subsection{Background and Objective}

This report presents a model for measuring the benefits of improved accuracy in test equipment. Although the model could be applied to many types of test equipment, the focus of this report is on that broad category of electronic test equipment commonly referred to as Automatic Test Equipment (ATE). For purposes of this discussion, ATE is defined as electronic test equipment that is controlled by microprocessors or programmable computers and is capable of high speed testing of individual electronic components, printed circuit boards, wiring harnesses, or entire electronic system assemblies.1

The origin of expected improvements in the accuracy of ATE lies in a proposal by the National Bureau of Standards (NBS) Center for Electronics and Electrical Engineering (CEEE) to develop prototypes for and support the implementation of a new calibration system that satisfies the special requirements of ATE. This proposed system, called Dynamic Transport Standards (DTS), would address two shortcomings of the current approach: "...(1) the lack of adequate ATE calibration in its operational environment under operational conditions at the UUT [unit under test] terminals and (2) the extensive range extension and bootstrapping activities in the building up of multi-parameter multi-level standards in numerous standards and calibration

${ }^{1}$ This definition is adapted from an unsigned article, "Electronic Component Testing with ATE" (Part I), Quality, Vol. 20, No. 10 (October 1981), pp. 16-20. 
laboratories in order to achieve traceability to national standards at NBS."I

Two types of improvements related to the performance of ATE could result from the use of the DTS system of calibration, once it is fully implemented. These potential improvements would both be in the form of reductions in the overall measurement error of ATE. The first improvement is a decrease in the systematic error or bias present in the test equipment measurements. The second type of improvement possible in the accuracy of ATE involves a decrease in the random measurement error of the test results. This second type of improvement is equivalent to an increase in measurement precision. The benefits of both these types of improved accuracy (reductions in measurement error) are determined by the model presented in this report.

\subsection{Scope}

The model is stochastic in the sense that it is based on two probability distributions and the measures of the benefits from improved accuracy are stated in terms of probabilities. The probability distributions are those of the UUT performance ${ }^{2}$ being tested and of the measurement error of the test equipment. The model can be used to analyze accuracy improvements for practically any application of test equipment as long as these two probability

I Barry A. Bell and Oskars Petersons, "ATE Calibration by Means of Dynamic Transport Standards," Proceedings of Autotestcon 81: International Automatic Testing Conference (Orlando, FL, October 19-21, 1981), Institute of Electrical and Electronic Engineers (IEEE Catalogue No. $81 \mathrm{CH} \mathrm{1716-0),} \mathrm{1981,}$ pp.280-287.

2UUT performance refers to the value of the particular UUT attribute that is being measured by the test equipment. 
distributions can be assumed to be normal. That is, the attribute of the UUT that is being tested as well as the test equipment measurement error must both be approximately normally distributed.

The measures of benefits determined by the model are based on reductions In the probabilities of the two types of errors possible with every test situation: Consumer's Loss (CL) and Producer's Loss (PL).1 CL is the probability of accepting a UUT that does not conform to the performance specifications for the attribute being tested. PL is the probability of rejecting a UUT that does in fact conform to the performance specifications. The terms "consumer" and "producer" are used to indicate which interest group would typically bear the cost of each error type in a production testing context. During product warrantee periods, however, most of the cost arising from CL would typically be borne by producers. Moreover, when testing is being conducted as part of a maintenance function, the costs of both CL and PL usually remain within the organization.

The model expresses both probabilities, CL and PL, as explicit functions of measurement bias (systematic error), represented by the mean of measurement error, and of measurement imprecision, represented by the standard deviation of measurement error. These functions can be used to calculate directly the benefits, as measured by lower probabilities of errors, from reduced measurement blas and/or imprecision. When applied to a case study, an economic value, in terms of dollars saved per time period, can be established for these

1These probabilities are also referred to as Consumer's Risk and Producer's Risk, respectively. 
reduced probabilities. The economic value depends on the number of tests conducted in a time period and on the particular test situation being analyzed. Multiplication of each probability reduction by the number of items to be tested gives the expected reduction in the number of occurrences of each type of test error. The economic value of each reduced error occurrence can then be determined by identifying and categorizing the cost consequences of a single CL and PL occurrence. Separate estimates of the value of each cost consequence have to be derived. Examples of such cost consequences for a CL occurrence are field repair costs, accidents due to equipment failure, and for military applications the possible effects on readiness and mission success rates. Examples of cost implications for a PL occurrence are unnecessary diagnostic and repair costs, the costs of unnecessary retesting (including packing and shipping to higher echelon laboratories), excessive inventory of parts and UUTs because of downtime, and reduced production yields.

Because testing is conducted for a variety of purposes, the applicability as well as the dollar value of each of these cost implications (among others that may be identified) can vary greatly depending on the particular test situation belng analyzed. Examples of the many test applications possible are production testing both at intermediate stages and at the final product stage (i.e., outgoing tests), incoming testing of components to be used in manufacturing, and maintenance testing. The economic model presented in this report can be used to analyze all of these test applications, provided the basic nature of the measurement process is analog rather than digital. 
That is, the principal characteristic of the UUT that is being measured must be a continuous variable rather than a binomial or other type of discrete variable. This requirement is not too restrictive, however, because even when semiconductor devices that are primarily digital in design are being tested, some critical analog measurements must be made.

This economic model may be employed to guide managers in making cost-effective decisions regarding research planning, maintenance and procurement policy, and product quality assurance functions. For example, by determining the effects of alternative calibration support strategies on CL and PL, the model can assist program managers in selecting areas of calibration research that have the highest potential payoff. In the area of maintenance and procurement policy, the model can be used to optimize the frequency and quality of calibration procedures with existing test equipment, as well as to select the best new test equipment through a comparison of additional costs with the economic benefits of expected accuracy improvements. Moreover, in the area of quality assurance, the model can be applied to determine, for a particular product and test environment, which test specifications optimize the economic trade-off between CL and PL.

\subsection{Organization}

The next section describes the mathematical formulation of the model for calculating CL and PL as functions of the mean and the standard deviation of the measurement error. Section 3 discusses the results of applying the model to an analysis of how changes in the mean and standard deviation of the measurement error can be expected to affect CL and PL. Section 4 summarizes the results and describes several useful applications of the model. 
Appendix A gives complete documentation for BINORMAL.CL-PL, the interactive computer program developed to calculate CL and PL for a wide variety of test situations. Appendix B provides plots of CL and PL as functions of the mean and standard deviation of measurement error, and illustrates how the plots can be used to derive estimates of CL and PL for certain cases. 


\section{Mathematical Formulation of the Model}

This section begins by summarizing the work of statisticians who developed the basic model for computing CL and PL in the context of 100 percent testing. Then this basic model is extended to incorporate the effect of possible changes in the accuracy of the test equipment. These accuracy changes are mathematically specified both in terms of uncorrected measurement bias and random measurement error. The notation that will be used in the model is summarized in table 2.1 .

\subsection{The Basic Model}

Three key papers published in the $1950^{\prime}$ s describe how to use CL and PL when selecting appropriate test specification limits. Eagle defined the basic concepts of $\mathrm{CL}$ and PL and published plots of their values as functions of the test specification limits and the random measurement error for a fixed performance specification. 1 Eagle's discussion was restricted to the case in which both the upper and lower test specification limits and the performance specification limits are symmetric with respect to the mean of the performance distribution. In an article published in the same issue of Industrial Ouality Control, Grubbs and Coon maintained this symmetry restriction while applying the model to optimize the decision of how to set the test specification in relation to the performance specifications. 2 They developed decision rules

${ }^{1}$ Alan R. Eagle, "A Method for Handling Errors in Testing and Measuring," Industrial Quality Control, Vol. 10, No. 5 (March 1954), pp 10-15.

${ }^{2}$ Frank E. Grubbs and Helen J. Coon, "On Setting Test Limits Relative to Specification Limits," Industrial Quality Control, Vol. 10, No. 5 (March 1954), pp 15-20. 
Table 2.1 Notation Used in the Model and in Appendix B.

UUT

CL

PL

u

$\varepsilon$

m

$\rho$

$\mu_{u}$

$\sigma_{\mathbf{u}}$

$\mu_{\varepsilon}$

$\sigma_{\varepsilon}$

$\mathrm{S}_{\mathrm{U}}$

$\mathrm{S}_{\mathrm{L}}$

TA
Unit Under Test: product or product component that is being tested.

Consumer's Loss: the probability of accepting a UUT that does not conform to the performance specifications for the attribute being tested.

Producer's Loss: the probability of rejecting a UUT that does in fact conform to the performance specifications for the attribute being tested.

Performance values of the particular UUT attribute that is being tested.

Error values that occur when $u$ is measured with the test equipment.

Observed measurement values of $u$ as taken by the test equipment, $\mathrm{m}=u+\varepsilon$.

Statistical correlation between $u$ and $\mathrm{m}$.

Mean of the UUT performance distribution.

Standard deviation of the UUT performance distribution.

Mean of the measurement error distribution, also known as undetected systematic measurement error or bias.

Standard deviation of the measurement error distribution, also known as measurement imprecision.

Upper specification limit for UUT performance.

Lower specification limit for UUT performance.

Tolerance adjustment of the test equipment: the difference between the performance specification limits and the test specification limits. In this discussion, TA is assumed to be equal for upper and lower specifications. TA is an adjustment typically made to allow for measurement error in the test equipment. A positive $T A$ value means that the test specifications lie inside the performance specifications. Thus, a positive TA makes the test specifications more stringent (i.e, more likely to reject a UUT) than the unadjusted performance specifications. 
Table 2.1 Notation Used in the Model and in Appendix B (Cont'd)

Symbol

Definition

$\begin{array}{ll}\mathrm{S}_{\mathrm{U}} \mathrm{TA} & \text { Upper test specification limit. } \\ \mathrm{S}_{\mathrm{L}}+\mathrm{TA} & \text { Lower test specification limit. } \\ \mathrm{k}_{1} & \text { Standardized upper performance specification limit. } \\ \mathrm{k}_{2} & \begin{array}{l}\text { Negative of the standardized lower performance } \\ \text { specification limit. }\end{array} \\ \mathrm{q}_{1} & \text { Standardized upper test limit. } \\ \mathrm{q}_{2} & \text { Negative of the standardized lower test limit. }\end{array}$


for setting the test specification limits in order to optimize three alternative objective functions: (1) to make CL and PL equal; (2) to minimize the sum of CL and PL; and (3) to minimize the weighted sum of CL and PL, where the weights could be interpreted as the relative costs of a single occurrence of each type of error. Five years later, Owen and Wiesen published a method of calculating CL and PL using graphs and extended the basic model to include the analysis of one-tail tests as well as of asymmetric settings on both the test specification limits and the performance specification limits for two-tail tests.1 (A two-tail test has both upper and lower test specification limits, while a one-tail test has only one of these limits.) For these additional cases, Owen and Wiesen develop optimal decision rules for setting test limits using the three objective functions suggested by Grubbs and Coon. In addition, they develop test limit decision rules based on an interesting objective function suggested by Tingey and Merrill, 2 namely to minimize the sum of the costs of CL and PL when the cost per occurrence of CL varies in proportion to the degree of nonconformance of the accepted product (i.e., how far out of specifications the product is).

The general test situation being analyzed in all of the above modeling efforts is that in which a single measurement is taken on a continuously variable characteristic of every UUT in the process being monitored.

\footnotetext{
${ }^{I}$ D. B. Owen and J. M. Wiesen, "A Method of Computing Bivariate Normal Probabilities: With an Application to Handling Errors in Testing and Measuring," The Bell System Technical Journal, Vol. 38 (March 1959), pp. 553-572.

2F. H. Tingey and J. A. Merrill, "Minimum Risk Specification Limits," AEC Research and Development Report IDo-16396 (Phillips Petroleum Co., Atomic Energy Division, Contract No. AT (10-1)-205), July 30, 1957 .
} 
As indicated in the previous section, the process may be manufacturing, screening of input components prior to assembly, or periodic maintenance. The test equipment with which the measurements are taken is subject to random error. Because of the presence of measurement error there is a nonzero probability that bad units will be accepted (i.e., CL), and similarly a nonzero probability that good units will be rejected (i.e., PL). The basic model formulated in the above papers assumes that the distribution of the UUT performance characteristic being measured is normal (Gaussian) with mean $\mu_{u}$ and standard deviation $\sigma_{\mathrm{u}}$. It is further assumed that the distribution of the test measurement error is normal with a mean of zero and standard deviation $\sigma_{\varepsilon} \bullet^{1}$ The upper and lower UUT performance specification limits are based on engineering considerations and assumed to be set at $\mathrm{S}_{U}$ and $\mathrm{S}_{\mathrm{L}}$, respectively.2 To adjust for the random error known to be present in the test equipment measurements, the test specification limits are generally assumed to be set at values different from $S_{U}$ and $S_{L}$. The magnitude and direction of this adjustment is given by TA, the tolerance adjustment of the test equipment. 3 Thus, the upper test specification limit is set at $S_{U}-\mathrm{TA}$ and the lower limit is set at $\mathrm{S}_{\mathrm{L}}+\mathrm{TA}$. Thus, for $\mathrm{TA}>0$ the test limits are placed inside the UUT performance specification limits, which makes the test

${ }^{1}$ In the formulation of Owen and Wiesen, the mean of the test measurement error distribution can assume nonzero values. However, this bias is generally assumed to be known and corrected for in setting the test specification limits.

2 This discussion of the basic model and its extensions focuses on two-tail tests. The computer program described in appendix A also covers upper and lower one-tail tests.

${ }^{3}$ This formulation assumes that the tolerance adjustment is equal for both tails. The computer program in appendix A permits unequal tolerance adjustments. 
limits more stringent (i.e., more likely to reject UUTs) than if there were no tolerance adjustment. If a quality assurance manager considered measurement errors of a particular test application to be insignificant relative to the variance in the UUT performance distribution, TA would typically be set at zero. In this case the test limits would equal the performance specifications. When measurement errors cannot be ignored, a nonzero value for TA is needed. For a given test equipment precision, the value assigned to TA should be determined by the relative cost consequences of each occurrence of $\mathrm{CL}$ and $\mathrm{PL}$. The more costly is an occurrence of $\mathrm{CL}$, the greater TA should be in order to make the test more stringent and less likely to accept bad UUTs. Conversely, the more costly is an occurrence of PL (relative to CL), the smaller (perhaps even negative) TA should be in order to make the test less stringent and less likely to reject good UUTs. Thus, when the precision of test equipment is given, the economic trade-off between CL and PL is to be balanced by setting the test limits with respect to the performance specifications, that is, by choosing the appropriate value for TA. Indeed, the primary motivation of this basic model, as developed in the $1950^{\prime} \mathrm{s}$, is to provide a rational basis for setting test limits.1

The formulas for calculating $\mathrm{CL}$ and PL are based on the bivariate normal probability distribution and have been worked out by Owen and Wiesen.2 The performance values of the particular UUT attribute that is being measured and tested are denoted by $u$. These values are measured subject to error, $\varepsilon$, so that the observed measurement as taken by the test equipment is

The very title of the article by Grubbs and Coon is, "On Setting Test Limits Relative to Specification Limits." In the Owen and Wiesen article, the major concluding section is entitled, "Special Criteria for Determining Specification Limits."

${ }^{2}$ See section III, "Errors in Testing and Measuring," in Owen and Wiesen, pp. 562-569. 
given by $m=u+\varepsilon$. As long as $u$ and $\varepsilon$ are independent, the correlation between $u$ and $m$ is given by $\rho=\sigma_{u}\left(\sigma_{u}^{2}+\sigma_{\varepsilon}^{2}\right)-0.5$. Based on the conceptual definitions of CL and PL, the following expressions are derived in Owen and Wiesen:

$$
\begin{aligned}
& C L=L\left(k_{1},-q_{2}, \rho\right)-L\left(k_{1}, q_{1}, \rho\right)-L\left(k_{2}, q_{2}, \rho\right)+L\left(k_{2},-q_{1}, \rho\right), \\
& P L=C L+G\left(k_{1}\right)+G\left(k_{2}\right)-G\left(q_{1}\right)-G\left(q_{2}\right),
\end{aligned}
$$

where $L(k, q, \rho)$ is the upper tail probability for the standardized bivariate normal distribution,

$$
(2 \pi)^{-1}\left(1-\rho^{2}\right)-0.5 \int_{k}^{\infty} \int_{q}^{\infty} \exp \left[\left(2 \rho u m-u^{2}-m^{2}\right) / 2\left(1-\rho^{2}\right)\right] d m d u,
$$

and $G(k)$ is the standardized univariate normal cumulative distribution function,

$$
(2 \pi)-0.5 \int_{-\infty}^{k} \exp \left[-u^{2} / 2\right] d u
$$

The arguments, $k_{1}$ and $k_{2}$, of the $L$ and $G$ functions are the standardized upper performance specification limit and the negative of the standardized lower performance specification limit, respectively, and are defined as follows:

$$
\begin{aligned}
& k_{1}=\left(S_{U}-\mu_{u}\right) / \sigma_{u}, \text { and } \\
& k_{2}=-\left(S_{L}-\mu_{u}\right) / \sigma_{u}
\end{aligned}
$$

The arguments, $q_{1}$ and $q_{2}$, are the standardized upper test limit and the negative of the standardized lower test limit, respectively, and are defined as follows: 


$$
\begin{aligned}
& q_{1}=\left(S_{U}-T A-\mu_{u}\right)\left(\sigma_{u}^{2}+\sigma_{\varepsilon}^{2}\right)-0.5 \text {, and } \\
& q_{2}=-\left(S_{L}+T A-\mu_{u}\right)\left(\sigma_{u}^{2}+\sigma_{\varepsilon}{ }^{2}\right)-0.5
\end{aligned}
$$

The correctness of the formula for CL given in expression (2.1) can be demonstrated by examining each of its four terms (i.e., the L functions). Recall the basic definition of $\mathrm{CL}$ as the probability of accepting a bad UUT. The first two terms in expression (2.1) address only those bad UUTs that exceed the upper performance specification, $S_{U}$. The first term, $L\left(k_{1},-q_{2}, \rho\right)$, is interpreted as the joint probability that the true performance value of a UUT being tested exceeds the upper performance specification (i.e., the UUT is bad on the high side), and that the test result is greater than the lower test specification (i.e., the UUT is not rejected by falling below the lower test specification). Since it is highly improbable for a UUT that exceeds $S_{U}$ to have a test result falling below the lower test limit, this first term represents virtually all of the UUTs whose true performance values are bad on the high side. The second term of $\mathrm{CL}, \mathrm{L}\left(\mathrm{k}_{1}, \mathrm{q}_{1}, \rho\right)$ is the joint probability that a UUT exceeds the upper performance specification (i.e., a bad UUT), and that the test result exceeds the upper test limit (i.e., the UUT is rejected by falling above the acceptable limit). In other words, the second term in expression (2.1) can be interpreted as the joint probability of a UUT that is bad on the high side being correctly rejected by exceeding the upper test 1imit. Thus the difference between the first two terms of CL, $L\left(k_{1},-q_{2}, \rho\right)-L\left(k_{1}, q_{1}, \rho\right)$, represents the probability that a UUT that is bad on the high side will pass the test and be accepted. Thus, this difference represents the upper tail portion of CL. Similarly, the remaining two terms in the CL formula represent the probability a UUT that is bad on the low side will pass the test and be accepted. Thus the difference given by the third and fourth terms of expression (2.1), $-\mathrm{L}\left(\mathrm{k}_{2}, \mathrm{q}_{2}, \rho\right)+\mathrm{L}\left(\mathrm{k}_{2},-q_{1}, \rho\right)$, represents the lower tail portion of $\mathrm{CL}$. 


\subsection{Extensions of the Model}

In this subsection the basic model discussed above is extended to permit the analysis of the effects of changes in test equipment accuracy on CL and PL. The elements of accuracy to be analyzed include both uncorrected measurement bias and random measurement error.

If a systematic error or bias is present in a measurement system and its magnitude and direction are exactly known, then the value of TA can be adjusted accordingly. This type of known and corrected bias is not of much interest because it has no effect on CL and PL. On the other hand, a measurement bias which is unknown and uncorrected will affect both CL and PL because such a bias would result in different values for $q_{1}$ and $q_{2}$ in the formulas.

Denote $\mu_{\varepsilon}$ to be the undetected systematic measurement error (bias) in the test equipment. Because of this bias, the mean of the observed measurement now becomes $\mu_{m}=\mu_{u}+\mu_{\varepsilon}$. However, the standard deviation of $m$ is unaffected by the bias as long as the error and the performance value are independent. That is, $\sigma_{m}=\left(\sigma_{u}^{2}+\sigma_{\varepsilon}^{2}\right) 0.5$, as was the case in the absence of bias. Thus, $\rho$, which is the ratio of $\sigma_{u}$ to $\sigma_{m}$, is also unaffected by the introduction of the bias.1

The basic model must be modified to take into account explicitly the presence of undetected measurement bias with its consequent change in the mean of the observed measurement, $\mu_{m}$. The arguments, $k_{1}$ and $k_{2}$, given in expression (2.5) were derived by standardizing the upper and lower performance specification limits and taking the negative of the lower standardized limit. The procedure for standardizing involves subtracting the mean and dividing by the standard deviation of the relevant distribution. Since $k_{1}$ and $k_{2}$ represent

TOwen and Wiesen, p. 562. 
limits on the UUT distribution, standardizing involves subtracting $\mu_{\mathrm{u}}$ and dividing by $\sigma_{u}$. The introduction of undetected measurement bias has no effect on either of these parameters of the UUT distribution, so that the arguments, $k_{1}$ and $k_{2}$, are unaffected by such bias. Consequently, the definitions of $k_{1}$ and $k_{2}$ found in expression (2.5) are to be used in both the basic model (with no measurement bias) and the extended model (with measurement bias).

In contrast, the introduction of undetected measurement bias has a decided effect on the arguments, $q_{1}$ and $q_{2}$, defined for the basic model in expression $(2.6)$. These arguments represent limits on the observed measurement distribution (i.e., the distribution of m). Consequently, standardizing the test limits, $\mathrm{S}_{U}+\mathrm{TA}$ and $\mathrm{S}_{\mathrm{L}}-\mathrm{TA}$, involves subtracting the mean of $m$, which has changed from $\mu_{u}$ in the basic model to $\mu_{u}+\mu_{\varepsilon}$ in the extended model because of the presence of nonzero measurement bias $\left(\mu_{\varepsilon}\right)$. As noted above, the standard deviation of the observed measurement, $\sigma_{m}$, remains unaffected by the measurement bias. Standardizing the upper and lower test limits using the new value of $\mu_{\mathrm{m}}$ and taking the negative of the standardized lower test limit result in the following new definitions of the arguments $q_{1}$ and $q_{2}$ to be used in the extended model:

$$
\begin{aligned}
& q_{1}=\left(S_{U}-T A-\mu_{u}-\mu_{\varepsilon}\right)\left(\sigma_{u}{ }^{2}+\sigma_{\varepsilon}{ }^{2}\right)-0.5 \text {, and } \\
& q_{2}=-\left(S_{L}+T A-\mu_{u}-\mu_{\varepsilon}\right)\left(\sigma_{u}{ }^{2}+\sigma_{\varepsilon}{ }^{2}\right)-0.5 .
\end{aligned}
$$

In summary, the introduction of an undetected measurement bias has the effect of reducing $q_{1}$ by an amount equal to $\mu_{\varepsilon}\left(\sigma_{u}{ }^{2}+\sigma_{\varepsilon}{ }^{2}\right)-0.5$ and of increasing $q_{2}$ by the same amount.l This explicit introduction of the bias,

\footnotetext{
TOwen and Wiesen (p. 567) suggest that an undetected bias should be embodied in the model as a change in the UUT performance specification limits, but clearly the test bias only affects the observed measurement result, $\mathrm{m}$, and leaves the underlying UUT distribution and performance limits unchanged.
} 
$\mu_{\varepsilon}$, constitutes a generalization of the basic model. The basic model is now seen as a special case of the more general, extended model. The basic model represents the case in which $\mu_{\varepsilon}$, the undetected measurement bias, is zero. Consequently, the definitions of $q_{1}$ and $q_{2}$ in expression (2.7) can be used in al1 cases. This generalization of the model permits direct calculation of the effect of any given undetected bias on CL and PL. In addition, this extended model can be used to measure the effect of changing (i.e., increasing, reducing, or even eliminating) an undetected bias by any amount. In this way, the economic effects of any improvements in test equipment accuracy related to systematic measurement error can be determined. The origin of such biasrelated accuracy improvements could be better equipment, better operation and maintenance personnel or procedures, or an improved system of calibration, such as is expected if the DTS system is implemented for ATE.

If no measurement bias is present, the basic model could be used to analyze the effects of imprecision (i.e., $\sigma_{\varepsilon}$ ). On the other hand, if changes of test equipment precision are to be analyzed in the presence of bias, then the extended model that explicitly incorporates a term for measurement bias in the formulas for CL and PL must be used. Indeed, both analyses can be conducted using the extended model, because the bias term $\mu_{\varepsilon}$ can easily be set equal to zero in the $q_{1}$ and $q_{2}$ formulas.

In the CL and PL formulas of the extended model, $\sigma_{\varepsilon}$ appears as part of the denominators of $q_{1}, q_{2}$ and $\rho$. Thus, the determination of the effect on CL and PL of an improvement in precision (i.e., a reduction in $\sigma_{\varepsilon}$ ) is accomplished by first computing CL and PL using the original (lower precision) value of $\sigma_{\varepsilon}$ and then recomputing $C L$ and PL using the improved precision value of $\sigma_{\varepsilon}$. The difference between the two computations represents the reduction in the 
probabilities of occurrence of the CL and PL errors that could result from improving the precision (lowering $\sigma_{\varepsilon}$ ) of the test equipment. The improved precision could be realized by (1) more advanced test equipment, (2) better operation and maintenance procedures that reduce the random measurement error arising from such sources as electromagnetic interference, temperature, humidity, and pressure, or (3) better calibration support systems. Conversely, the model could determine the cost consequences, in terms of increased values of CL and PL, of using less precise test equipment.l

This concludes the discussion of the basic model and the extended version of the model which permits the analysis of the effects on CL and PL of changes in the systematic and/or random measurement errors of test equipment. The next section summarizes the results of applying the extended model to determine the magnitude, direction, and general pattern of these effects on CL and PL for a broad range of test situations.

\footnotetext{
$1^{1}$ There are some circumstances in which reducing the measurement bias could actually lead to increases in CL and PL. Similarly, it is possible that a decrease in $\sigma_{\varepsilon}$ may result in an increase in CL or PL. These cases are discussed in section 3 .
} 


\section{Results}

An interactive computer program has been developed which calculates the values of the probabilities, CL and PL, as defined in the extended model described in section 2. Complete documentation and a listing for this program, BINORMAL.CL-PL, are provided in appendix $A$ of this report. The program was used to calculate CL and PL for a wide range of assumed model parameter values. The objective of this section is to use the results of these calculations to indicate how changes in systematic measurement error $\left(\mu_{\varepsilon}\right)$ and in the standard deviation of measurement error $\left(\sigma_{\varepsilon}\right)$ affect CL and PL. The results reported here are all based on the case of two-tail tests with performance specifications and test limits both symmetric around the mean performance, $\mu_{u}$. So that the results can be easily generalized to other cases, the performance distribution is standardized (i.e., $\mu_{u}=0$, and $\sigma_{u}=1$ ).

\subsection{Effects of Systematic Measurement Error}

The analysis of the effects of systematic measurement error on CL and PL is conducted on two levels. The first level of analysis focuses on the direction of the effects of changing systematic error on CL and PL. The question is whether an increase in systematic measurement error would increase or decrease CL and PL. The second level of analysis concerns the general pattern and order of magnitude of these effects. The questions here are whether the effects increase with increases in systematic error and how large are the effects. The next subsection deals with the first level of analysis.

\subsubsection{Direction of Effects}

The directional effects of systematic measurement error on CL and PL were initially analyzed for 243 cases, each case being one combination of values 
for the three parameters: performance specification limits $\left(k_{1}=k_{2}\right)$; standard deviation of measurement error $\left(\sigma_{\varepsilon}\right)$; and test tolerance adjustment (TA). The values used for these three parameters are given in table 3.1, along with the four systematic error values used to analyze each case.

Because an increase in systematic measurement error represents a deterioration in the accuracy performance of the test equipment, one's intuitive expectation is that greater probabilities of wrong decisions, CL and PL, would result. Indeed, PL behaved as expected for all of the cases analyzed, while CL did so for most cases. The only exceptions occurred for large negative values of TA (i.e., when the test limits lie considerably outside the UUT performance specification limits), where CL decreased as a result of increasing the systematic measurement error. To indicate the bounds for these exceptions, it is useful to examine the critical values of the ratio

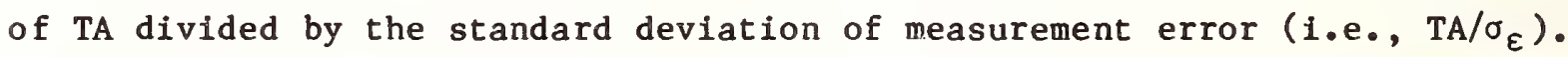
Critical values are to be interpreted as those values of the ratio, $\mathrm{TA} / \sigma_{\varepsilon}$, below which CL began to decrease with increasing systematic error. These critical ratios are presented in table 3.2 for the cases analyzed. That is, for values of $\mathrm{TA} / \sigma_{\varepsilon}$ below (1.e., larger in a negative direction than) the critical value given in the table, CL decreased when the systematic error was increased. The data in table 3.2 suggest two general patterns. First, the critical value of the ratio appears to increase (i.e., assumes a smaller negative value) for larger performance limits. Secondly, the critical ratio tends to decrease in value (i.e., assume a larger negative value) for smaller random errors. 
Table 3.1 Parameter Values and Systematic

Error Values Used to Analyze the Direction of

the Effect of Systematic Error on CL and PL.

Characteristic

Symbol

Values

Performance

$k_{1}=k_{2}$

$1,2,3$

Specification

Standard Deviation

$\sigma_{\varepsilon}$

$1 / 2,1 / 3,1 / 4,1 / 5,1 / 6,1 / 7,1 / 8,1 / 9,1 / 10$

of Measurement

Error

Tolerance

Adjustment

TA

$0, \pm 0.5 \sigma_{\varepsilon}, \pm 1.0 \sigma_{\varepsilon}, \pm 1.5 \sigma_{\varepsilon}, \pm 2.0 \sigma_{\varepsilon}$

Systematic

Measurement Error

$\mu_{\varepsilon}$

$0,0.5 \sigma_{\varepsilon}, 1.0 \sigma_{\varepsilon}, 1.5 \sigma_{\varepsilon}$ 
Table 3.2 Critical Values of $\mathrm{TA} / \sigma_{\varepsilon}$ Below Which CL Decreases with Increasing Systematic Error, for Various Symmetric Performance Limits and Standard Deviations of Measurement Error.

Standard Deviation of Measurement

Error

0.500

0.333

0.250

0.200

0.167

0.143

0.125

0.111

0.100

\section{Performance Limits}

$\mathrm{k}_{1}=\mathrm{k}_{2}=1$

$k_{1}=k_{2}=2$

$k_{1}=k_{2}=3$

$-0.5$

$-0.5$

0.0

$-1 \cdot 0$

$-0.5$

$-0.5$

$-1 \cdot 0$

$-0.5$

$-0.5$

$-1 \cdot 0$

$-1 \cdot 0$

$-0.5$

$-1 \cdot 0$

$-1.0$

$-1.0$

$-1 \cdot 5$

$-1.0$

$-1.0$

$-1.5$

$-1.0$

$-1.0$

$-1.5$

$-1.0$

$-1.0$

$-1.5$

$-1.0$

$-1.0$ 
Because of this contrary behavior of CL for large negative values of TA, an improvement in accuracy achieved by reducing systematic measurement error could theoretically result in an increase in the combined costs of CL and PL. For the range of TA values defined by table 3.2, PL will definitely decrease, but $\mathrm{CL}$ will increase. Thus, the net economic result could be positive or negative, depending on the relative sizes of the offsetting changes in CL and PL and on the relative economic costs of each occurrence of CL and PL.

Fortunately, this ambiguity concerning the overall economic effects of reducing bias can be resolved for all the measurement cases analyzed. In the first place, the problem does not arise very often because large negative TA values are not commonly used in practice. This is because in most applications the cost consequences of an occurrence of PL are less than those of CL. For example, the rejection of a good item (i.e., PL) may merely result in the costs of unnecessary retesting or the scrapping of a good component, while the acceptance of a bad item (i.e., CL) could result in failure in the field of an entire system with the associated costs of field diagnosis and repair or shipment to and repair in a test and repair depot. The greater the relative cost of $C L$ versus $\mathrm{PL}$, the more compelling is the need to guard against occurrences of $\mathrm{CL}$ by employing a larger (in the positive direction) value for TA.

A more definitive resolution of this ambiguity can be reached by appealing to an explicit relationship between the value of $\mathrm{TA}$ and the relative cost of CL versus PL. Grubbs and Coon derived such an explicit relationship by assuming that the objective of test policy is to minimize the expected 
value of the total cost of measurement error, 1 which is defined as follows:

$$
\mathrm{TC}=\mathrm{C}_{\mathrm{CL}} \cdot \mathrm{CL}+\mathrm{C}_{\mathrm{PL}} \cdot \mathrm{PL},
$$

where

$\mathrm{TC}=$ the expected value of the total cost of measurement error for each unit tested;

$\mathrm{C}_{\mathrm{CL}}=$ the economic cost of one occurrence of $\mathrm{CL}$;

$\mathrm{C}_{\mathrm{PL}}=$ the economic cost of one occurrence of $\mathrm{PL}$; and

CL,PL are as previously defined.

Since CL and PL are both functions of TA, Grubbs and Coon partially

differentiated this expression for TC with respect to TA. This procedure led to the following equation that determines the value of TA which minimizes TC:

$$
G\left(z_{1}\right)+G\left(z_{2}\right)=C_{P L} /\left(C_{C L}+C_{P L}\right)
$$

where

$$
\begin{aligned}
& z_{1}=-\left(1-\rho^{2}\right) 0.5\left(k+\sigma_{u} \mathrm{TA} / \sigma_{\varepsilon}{ }^{2}\right) ; \\
& z_{2}=-\left(1-\rho^{2}\right) 0.5\left[k+2 k\left(\sigma_{u} / \sigma_{\varepsilon}\right)^{2}-\sigma_{u} \mathrm{TA} / \sigma_{\varepsilon}{ }^{2}\right] ; \\
& k=k_{1}=k_{2} \text {, standardized performance specification limits as defined } \\
& \quad \text { in expression (2.5) above; and } \\
& G(z)=\text { standardized univariate normal cumulative distribution function, } \\
& \quad \text { as defined in expression (2.4) above. }
\end{aligned}
$$

1Frank E. Grubbs and Helen J. Coon, "On Setting Test Limits Relative to Specification Limits," p. 20. 
One application of this equation is to select the cost-minimizing value of TA for a given set of values for all the parameters: $C_{C L}, C_{P L}, \sigma_{u}, \sigma_{\varepsilon}$, and k. Another application, one more useful in resolving the ambiguity concerning the economic effects of reducing bias, is to solve for that value of the relative cost ratio, $C_{C L} / C_{P L}$, which satisfies the equation when the parameter values listed in table 3.1 are used for $k, \sigma_{\varepsilon}, \sigma_{u}$, and TA.1 The resulting cost ratio gives the relative cost consequences of a unit of CL and PL that would have to prevail in order for the TA value used in each case studied to be optimally selected. In other words, if it is assumed that the TA values for each case are selected with a view to minimizing $\mathrm{TC}$, then the equation permits us to specify the underlying relative cost ratio, $\mathrm{C}_{\mathrm{CL}} / \mathrm{C}_{\mathrm{PL}}$.

Following this procedure, one evaluates the two $G$ functions for the values of $z_{1}$ and $z_{2}$ specified by the parameter values for $k, \sigma_{\varepsilon}, \sigma_{u}$, and TA, and then sums them. This sum equals the righthand side of the equation, $\mathrm{C}_{\mathrm{PL}} /\left(\mathrm{C}_{\mathrm{CL}}+\mathrm{C}_{\mathrm{PL}}\right)$. By rearranging terms, one obtains the following expression for the relative cost of $\mathrm{CL}$ versus $\mathrm{PL}$ :

$$
\mathrm{C}_{\mathrm{CL}} / \mathrm{C}_{\mathrm{PL}}=\left[\mathrm{G}\left(\mathrm{z}_{1}\right)+\mathrm{G}\left(\mathrm{z}_{2}\right)\right]^{-1}-1
$$

Investigating the direction of the effect that reducing bias has on total measurement error costs is properly accomplished by determining the sign of the partial derivative of costs with respect to bias. Differentiating TC as given in expression (3.1), one obtains:

$$
\frac{\partial T C}{\partial \mu_{\varepsilon}}=C_{C L} \cdot \frac{\partial C L}{\partial \mu_{\varepsilon}}+C_{P L} \cdot \frac{\partial P L}{\partial \mu_{\varepsilon}} .
$$

${ }^{1}$ Though not explicitly given in table $3.1, \sigma_{u}=1$ for all the cases tested. 
The natural expectation is that a reduction in the bias would lead to lower total measurement error costs. This expectation is fulfilled provided the partial derivative expression is positive. Except for the case of large negative TA, when $\partial \mathrm{CL} / \partial \mu_{\varepsilon}$ becomes negative, both terms of the expression are positive, so that the derivative is positive and expectations are fulfilled. For those cases in which $\partial \mathrm{CL} / \partial \mu_{\varepsilon}$ is negative, the derivative will be positive if and only if the absolute value of first product, $\mathrm{C}_{\mathrm{CL}} \cdot \partial \mathrm{CL} / \partial \mu_{\varepsilon}$, is smaller than the second product, $C_{\mathrm{PL}} \cdot \partial \mathrm{PL} / \partial \mu_{\varepsilon} \cdot$ This requirement is equivalent to the condition:

$$
\mathrm{C}_{\mathrm{CL}} / \mathrm{C}_{\mathrm{PL}} \quad<\left|\frac{\partial \mathrm{PL} / \partial \mu_{\varepsilon}}{\partial \mathrm{CL} / \partial \mu_{\varepsilon}}\right|
$$

An analysis was conducted for all those cases for which $\partial \mathrm{CL} / \partial \mu_{\varepsilon}$ turned out to be negative. In every case, the condition (3.5) was fulfilled, and by a substantial margin. To illustrate these results, the following three figures present graphical comparisons of the two ratios of expression (3.5) for the case of $T A / \sigma_{\varepsilon}=-2.0 .1$ For the figures $3.1,3.2$, and 3.3 , the values of the symmetric performance specification limits are set at one $(k=1)$, two $(k=2)$, and three $(k=3)$ standard deviations, respectively, above and below $\mu_{u}$. The results are similar for the other three negative values used for $\mathrm{TA} / \sigma_{\varepsilon}$ (i.e., $-1.5,-1.0$, and -0.5). In each figure, the solid line indicates the

${ }^{1}$ These figures were derived using DATAPLOT, the graphical analysis computer software package developed by James J. Filliben of the National Bureau of Standards. For a summary description of this powerful package, see J. J. Filliben, "DATAPLOT - An Interactive High Level Language for Graphics, Non-Linear Fitting, Data Analysis, and Mathematics," Computer Graphics, Vol. 15, No. 3 (August 1981), pp 199-213. 


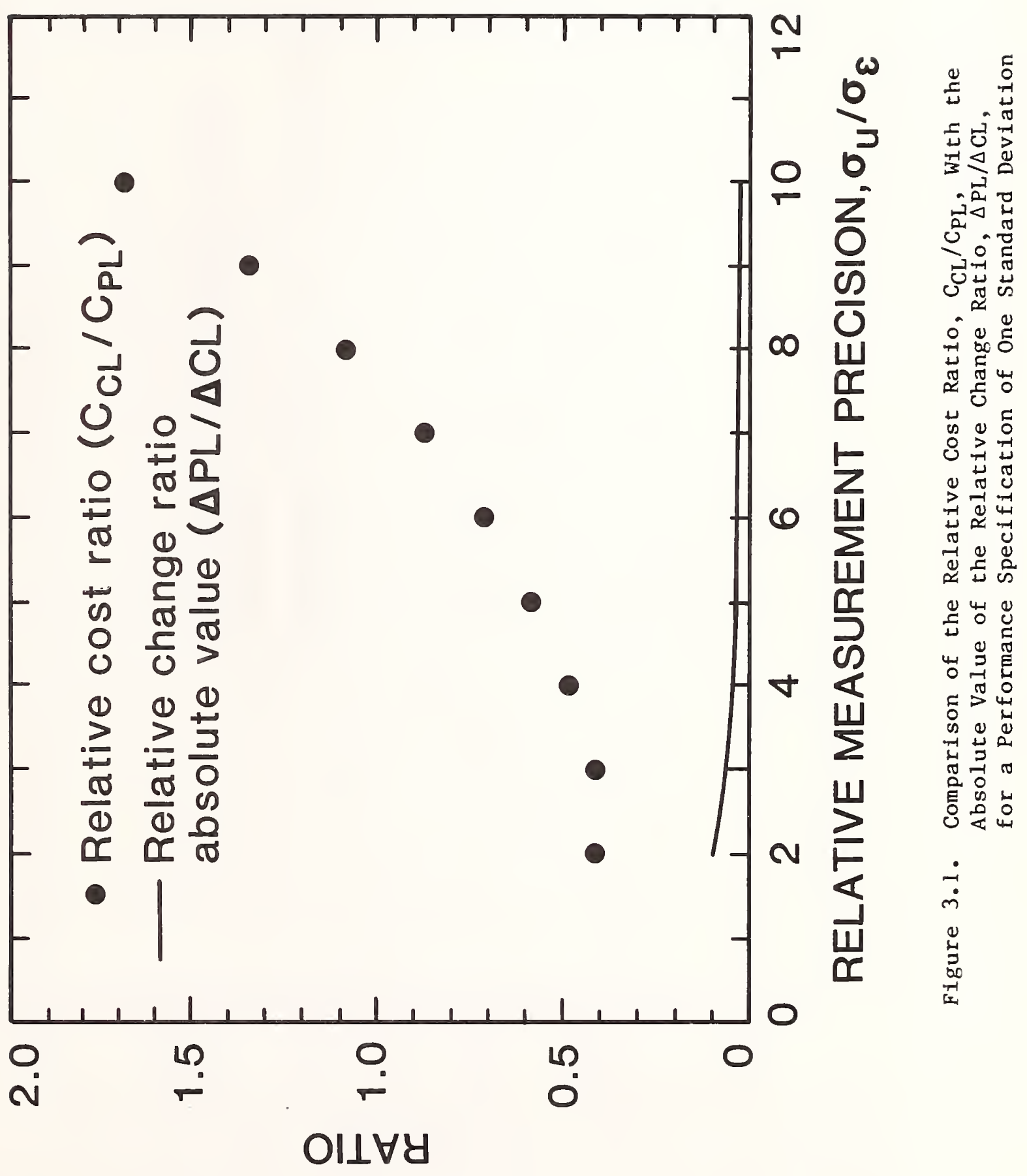




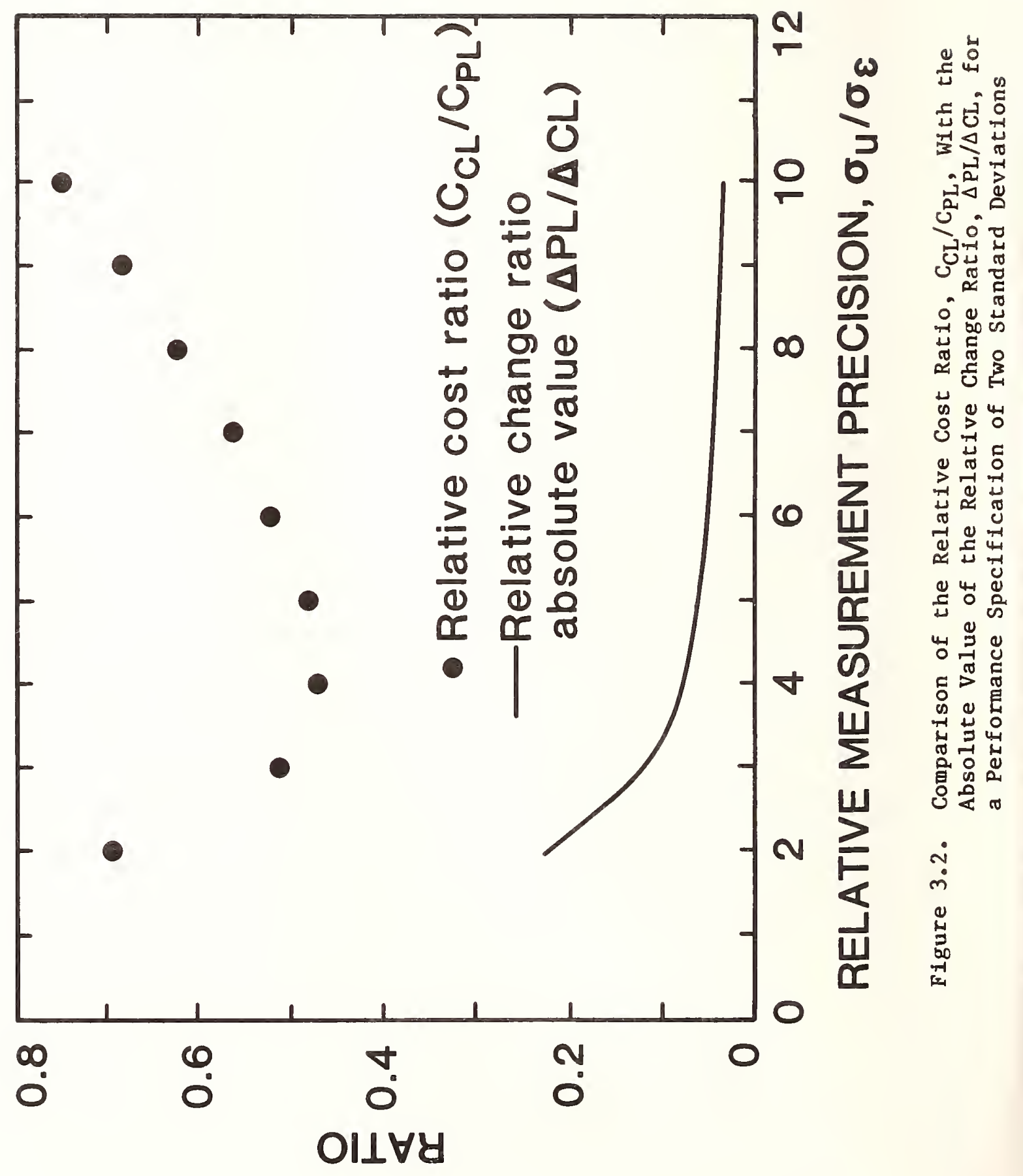




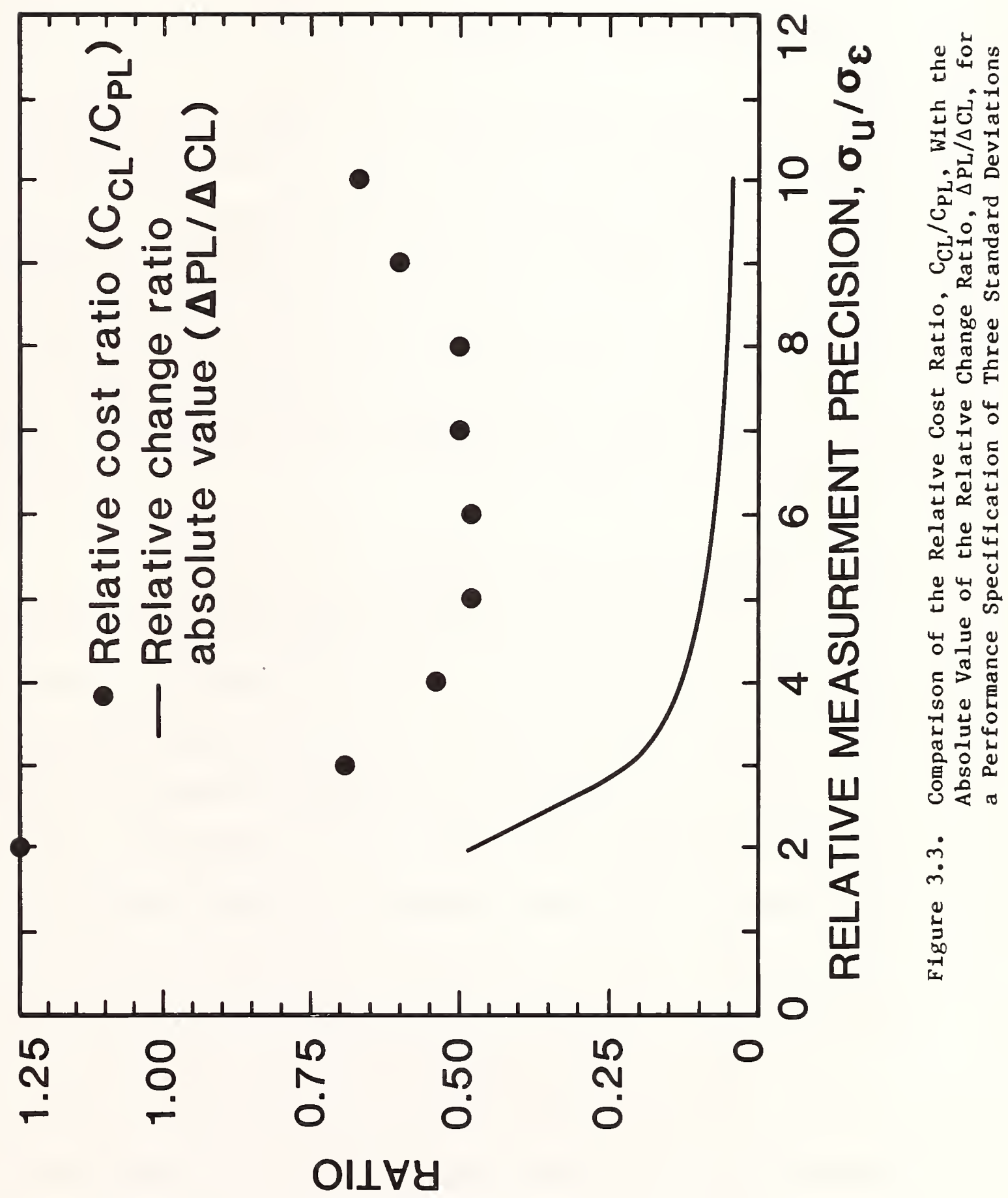


value of the relative cost ratio, $C_{C L} / C_{P L}$, as calculated from equation $(3.3)$. The data points (designated by dots) are absolute values of the relative change ratio, $\triangle \mathrm{PL} / \Delta \mathrm{CL}$, where

$$
\begin{aligned}
& \Delta \mathrm{PL}=\left(\mathrm{PL}_{\mu_{\varepsilon}}=0.5 \sigma_{\varepsilon}\right)-\left(\mathrm{PL}_{\mu_{\varepsilon}}=0\right), \text { and } \\
& \Delta \mathrm{CL}=\left(\mathrm{CL}_{\mu_{\varepsilon}}=0.5 \sigma_{\varepsilon}\right)-\left(\mathrm{CL}_{\mu_{\varepsilon}}=0\right) .
\end{aligned}
$$

The horizontal axis represents the relative measurement precision of each case analyzed as indicated by the ratio, $\sigma_{u} / \sigma_{\varepsilon}$. As each figure demonstrates, the relative cost ratio, $\mathrm{C}_{\mathrm{CL}} / \mathrm{C}_{\mathrm{PL}}$, is consistently less than the absolute value of the change in PL relative to $\mathrm{CL}$ for the entire range of measurement precision analyzed. Thus, for these cases the condition as stated in expression (3.5) is fulfilled, which demonstrates that an increase in $\mu_{\varepsilon}$ leads to greater measurement error costs, and conversely, that a decrease in $\mu_{\varepsilon}$ leads to lower error costs.

\subsubsection{Pattern and Magnitude of Effects}

Besides the direction of the effects that changing measurement bias has on CL and PL, the general pattern and order of magnitude of these effects need to be analyzed. For this purpose, the computer program BINORMAL.CL-PL was run to test additional cases which permit smaller increments in the values for systematic measurement error. There are 60 of these cases, each case being one combination of the three parameters: performance specification limits $\left(k_{1}\right.$ $=\mathrm{k}_{2}$ ); standard deviation of measurement error $\left(\sigma_{\varepsilon}\right)$; and test tolerance adjustment (TA). The values used for these parameters are presented in table 3.3, along with the set of nine systematic measurement error $\left(\mu_{\varepsilon}\right)$ values used to analyze each case. As was true for the computer runs listed in table 3.1, the value of $\sigma_{\mathrm{u}}$ for all these cases is also unity. Partial results of these 
Table 3.3 Parameter Values and Systematic Error Values Used to Analyze the Pattern and Magnitude of the Effect of Systematic Error on CL and PL.

\section{Characteristic}

Performance

Specification

Standard Deviation of Measurement Error

Tolerance

Adjustment
Systematic Measurement Error
Symbol

$\mathrm{k}_{1}=\mathrm{k}_{2}$

$\sigma_{\varepsilon}$

TA

$0,0.5 \sigma_{\varepsilon}, 1.0 \sigma_{\varepsilon}, 1.5 \sigma_{\varepsilon}, 2.0 \sigma_{\varepsilon}$

Values

$1,2,3$

$0.1,0.25,0.5,1.0$ $\mu_{\varepsilon}$

$0,0.25 \sigma_{\varepsilon}, 0.5 \sigma_{\varepsilon}, 0.75 \sigma_{\varepsilon}, 1.0 \sigma_{\varepsilon}$, $1.25 \sigma_{\varepsilon}, 1.5 \sigma_{\varepsilon}, 1.75 \sigma_{\varepsilon}, 2.0 \sigma_{\varepsilon}$ 
runs are presented in the figures B.I through B.6 of appendix B for the cases in which the performance specification limits equal two standard deviations of u (i.e., $\left.k_{1}=k_{2}=2\right)$. The pattern and magnitude of the measurement bias effects on CL and PL can be illustrated here with one set of these figures.

Figure 3.4 presents plots of the value of CL as a function of systematic measurement error for the case of $\sigma_{\varepsilon}=0.25 \sigma_{u}$. In order to examine the effect of TA, five plots are given in the figure, one for each of the five values of TA as specified in table 3.3. As noted in section 3.1.1, restricting TA to nonnegative values assures that there is a positively sloped relationship between systematic measurement error and CL. Figure 3.4 confirms this relationship, since all the plots indicate that CL increases as systematic error increases.

Figure 3.5 presents five plots of PL as a function of systematic error for the case of $\sigma_{\varepsilon}=0.25 \sigma_{u}$, each plot corresponding to a different positive value of $T A$, as specified in table 3.3. The consistently positive relationship between PL and systematic error that was noted in section 3.1 .1 is confirmed in all these plots of figure 3.5: larger systematic measurement errors result in greater values of $\mathrm{PL}$.

Throughout the entire range of values for systematic error, all of the PL plots and most of the CL plots (i.e., those for TA $\geqslant 1.0 \sigma_{\varepsilon}$ ) appear to be concave upward (i.e., positive second derivative of CL and PL with respect to systematic error). This upward concavity means that the impacts of increases in systematic error on CL and PL tend to increase with greater errors. For 


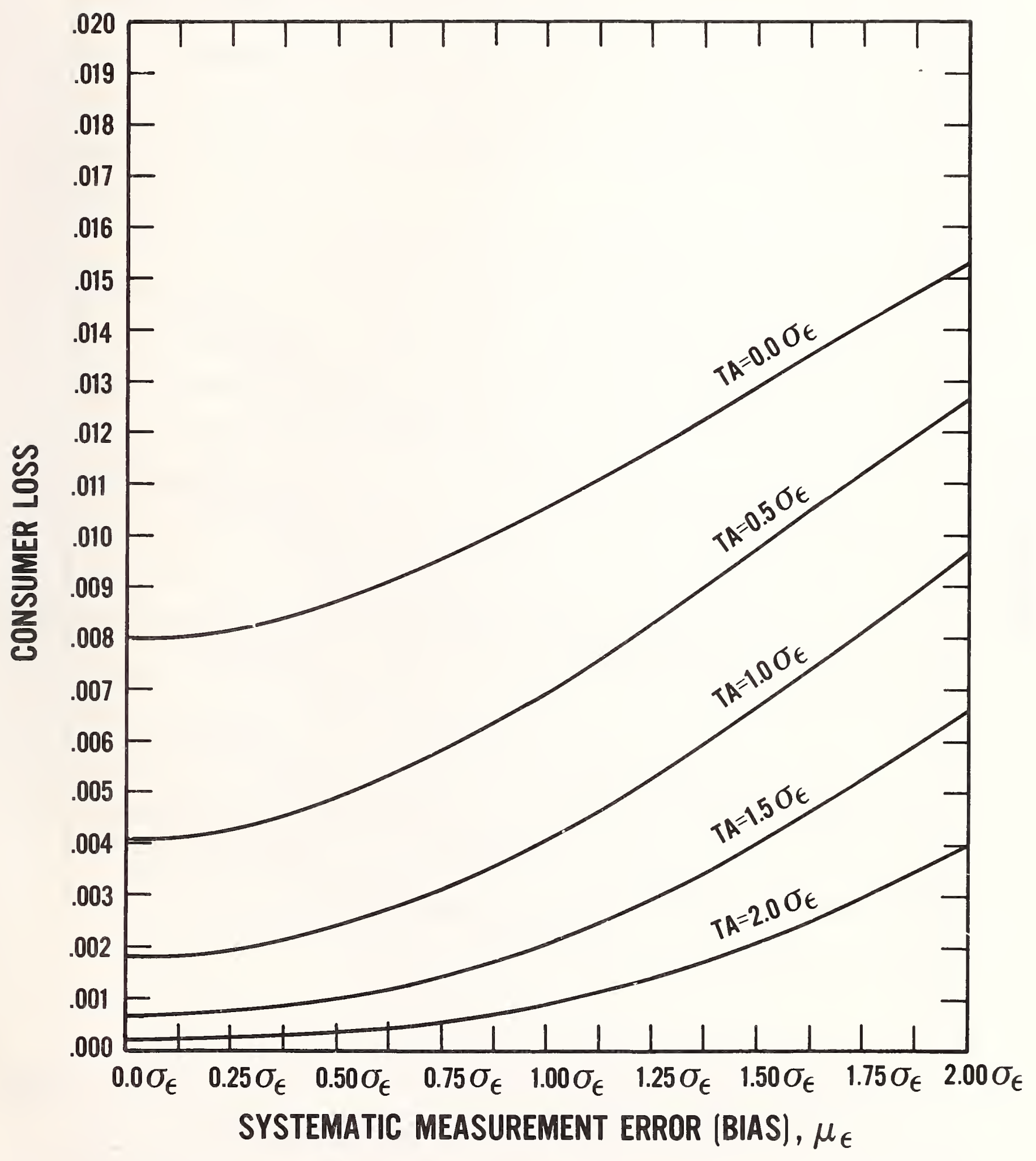

Figure 3.4. Consumer's Loss as a Function of Systematic Measurement Frror (Bias), for Characteristic Values of Test Tolerance 


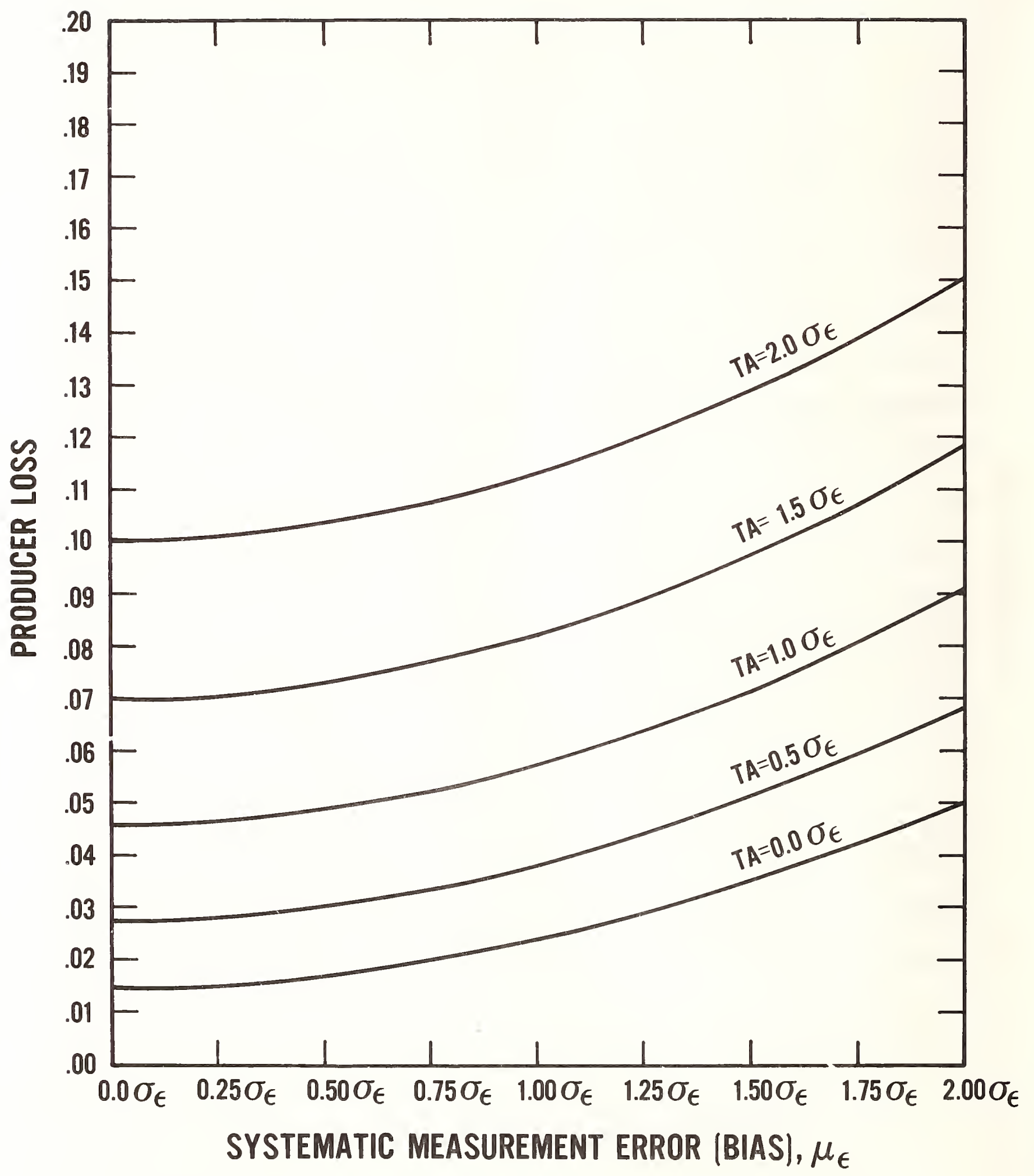

Figure 3.5. Producer's Loss as a Function of Systematic Measurement Error (Bias), for Characteristic Values of Test Tolerance 
example, the computed values on which figure 3.4 is based indicate that, for a TA value of $1.0 \sigma_{\varepsilon}$, CL increases from 0.001961 to 0.002403 to 0.003125 when systematic error increases from $0.25 \sigma_{\varepsilon}$ to $0.5 \sigma_{\varepsilon}$ to $0.75 \sigma_{\varepsilon}$, respectively. Thus, the first increment is only 0.000442 (i.e., 0.002403-0.001961), while the second increment is nearly twice as much, 0.000722 (i.e., 0.003125$0.002403)$

In spite of this general pattern of upward concavity for the plots as shown, one can observe virtual linearity and even inflection points (reversal to downward concavity) in two of the CL plots in figure 3.4 (i.e., those whose TA values are $0.5 \sigma_{\varepsilon}$ and 0 ). Indeed, even for the other data plots inflection points are eventually reached, but outside the range of systematic error values shown in the figures.

The reason for the eventual decrease in slope is that for any fixed value of the performance specification $\left(k_{1}=k_{2}\right)$, a certain percentage of all the UUTs will be good (within specifications) and the remaining percentage will be bad (outside specifications). These percentages represent theoretical limits on PL and CL, respectively. The actual limits on CL and PL for any particular test situation are often considerably lower than these theoretical percentages.1 The plots of CL and PL approach these actual limits asymptotically. The decrease in slope is not apparent in the figures for PL because the systematic measurement errors used in these computations are not

${ }^{1}$ For example, when $\mu_{\varepsilon}$ is positive and very large, the test will accept almost all of the bad UUTs that are in the lower rejection region, and thus contribute to CL. All of the bad UUTs in the upper rejection region, however, appear much worse than they are and so will be correctly rejected and will not contribute to CL. Therefore, in this case the actual limit on CL is only half of the theoretical limit (i.e., half of the total percentage of UUTs that are bad). 
large enough for the plots to reach their polnts of inflection. For some of the CL plots the points of inflection can be observed because they tend to occur at lower error values for CL than for PL.

Comparison of figures 3.4 and 3.5 reveals that for a given size systematic error, the value of TA has a significant but opposite effect on CL and PL. For example, a decrease in TA increases CL but decreases PL. The relationship between $\mathrm{CL}$ and TA makes sense if one remembers that TA affects how strict the test is; the smaller TA is, the wider (i.e., more accepting) the test specifications become. The reason for the increase in CL is as follows. A decrease in TA leaves the number of bad products unchanged, but increases the likelihood of a product's being accepted. Thus, more bad products will be accepted, so CL increases.

The converse is true for the relationship between PL and TA. A decrease in TA decreases the likelihood of a product's being rejected by widening the test specifications, and yet has no effect on the actual number of good units available to be rejected. As a result, fewer good products are rejected, so that PL decreases. In effect, the selection of a value for TA constitutes a choice in the trade-off between CL and PL. Indeed, the optimal selection of TA to minimize the total economic consequences of $\mathrm{CL}$ and $\mathrm{PL}$ is the basis of equation (3.2), developed above in section 3.1 .1 . 


\subsection{Effects of Random Measurement Error}

The analysis of the effects of random measurement error on CL and PL parallels the analysis of systematic error followed in subsection 3.1. The first level of analysis concerns the direction of the effects, while the second level focuses on their general pattern and magnitude.

\subsubsection{Direction of Effects}

The directional effects of random measurement error on CL and PL were analyzed for 108 cases, each case being one combination of values for the three parameters: performance specification limits $\left(k_{1}=k_{2}\right)$; systematic measurement error $\left(\mu_{\varepsilon}\right)$; and test tolerance adjustment (TA). The values used for these parameters are shown in table 3.4, along with the nine values of the standard deviation of measurement error $\left(\sigma_{\varepsilon}\right)$ used to analyze each case. Because $\sigma_{\varepsilon}$ is a variable in each case of this analysis, the values of TA and $\mu_{\varepsilon}$ are expressed in absolute terms rather than in units of $\sigma_{\varepsilon}$ as was done when the effects of systematic error were analyzed. For all these cases, the value of $\sigma_{\mathrm{u}}$ is assumed to be unity.

One would expect an increase in $\sigma_{\varepsilon}$ to lead to greater probabilities of incorrect decisions, in terms of both greater CL and greater PL. Indeed, for those cases most likely to occur in test situations, CL increased as $\sigma_{\varepsilon}$ increased. This expectation is fulfilled as long as the systematic error is less than or equal to the test tolerance adjustment. This finding can be

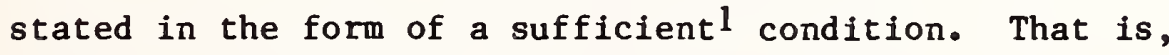

\footnotetext{
${ }^{1}$ There are a few cases in which $\mu_{\varepsilon}>$ TA and still $\frac{\partial C L}{\partial \sigma_{\varepsilon}}>0$.
} 
Table 3.4 Parameter Values and Standard Deviation of Measurement Error Values Used to Analyze the Direction of the Effect of the Standard Deviation of Measurement Error on CL and PL.

Characteristic

Performance

Specification

Systematic

Measurement Error

Tolerance

Adjustment
Symbol

$k_{1}=k_{2}$

$\mu_{\varepsilon}$

TA

$0, \pm 0.25, \pm 0.5, \pm 0.75, \pm 1.0$

\section{Values}

$1,2,3$

$0,0.5,1.0,1.5$
Standard Deviation of Measurement Error
$1 / 2,1 / 3,1 / 4,1 / 5,1 / 6,1 / 7,1 / 8$, $1 / 9,1 / 10$

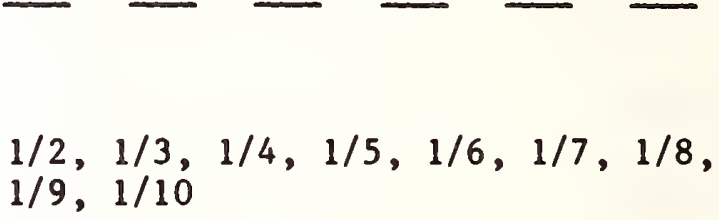

$\sigma_{\varepsilon}$ 


$$
\frac{\partial C L}{\partial \sigma_{\varepsilon}}>0 \text { if } \mu_{\varepsilon} \leq \mathrm{TA}^{1}
$$

In those actual test situations in which the order of magnitude of $\mu_{\varepsilon}$ is known, it is likely that TA will be set larger than $\mu_{\varepsilon}$ in order to control the size of CL, provided the economic cost of each CL occurrence is significant. If, however, the cost of CL is relatively low compared with that of PL, then the condition given in expression (3.8) is not likely to be fulfilled. That is, values smaller than $\mu_{\varepsilon}$ or even negative values will likely be assigned to TA. For such cases, the total cost of measurement error as specified in equation (3.1) should be analyzed along the lines followed in subsection 3.1 .1 .2

An increase in $\sigma_{\varepsilon}$ is also expected to cause an increase in PL. Once again, for the most likely test situations these expectations are fulfilled. For all the cases analyzed, PL consistently increased as a result of increasing $\sigma_{\varepsilon}$ as long as the performance specification exceeded the sum of the tolerance adjustment and the systematic measurement error. This finding can be summarized in terms of the condition statement:

$\frac{\partial \mathrm{PL}}{\partial \sigma_{\varepsilon}}>0$ if $\mathrm{k} \cdot \sigma_{\mathrm{u}}>\mathrm{TA}+\mu_{\varepsilon}$

where $k$ is the number of standard deviations that the performance limits lie above and below the mean for a symmetric test. That is, $\mathrm{k} \cdot \sigma_{\mathrm{u}}=\mathrm{S}_{\mathrm{U}}-\mu_{\mathrm{u}}=\mu_{\mathrm{u}}-\mathrm{S}_{\mathrm{L}}=0.5\left(\mathrm{~S}_{\mathrm{U}}-\mathrm{S}_{\mathrm{L}}\right)$.

1The partial derivative could theoretically be zero for the unlikely case in which the tolerance adjustment equals the performance specification. In this case, CL remains zero because there is no acceptance region and the only error possible is $\mathrm{PL}$, which remains at its maximum value.

${ }^{2}$ This analysis is proposed as the subject of future research. 
The condition stated in expression (3.9) will almost always be fulfilled in realistic test situations because the value $k \cdot \sigma_{u}$ represents one half of the entire range enclosed within the upper and lower performance specification limits. The sizes of $\mathrm{TA}$ and $\mu_{\varepsilon}$ derive from the distribution of the measurement error, $\varepsilon$, which typically has a narrower range, by an order of magnitude, than that of the UUT performance characteristic, $u$. Consequently, even the sum, $\mathrm{TA}+\mu_{\varepsilon}$, will be considerably smaller than half the performance range under normal circumstances. It is interesting to note, however, that it is theoretically possible for an increase in $\sigma_{\varepsilon}$ caused by a decrease in precision to lead to a decrease in the probability of rejecting good units (PL). An important objective for future research is to establish more exactly the conditions for assuring that $\mathrm{PL}$ increases as $\sigma_{\varepsilon}$ increases, either through more detailed simulations or the application of calculus.

\subsubsection{Pattern and Magnitude of Effects}

The pattern and magnitude of the effects on CL and PL of changes in measurement precision is established by running the computer program BINORMAL.CL-PL for a wide range of cases in which $\sigma_{\varepsilon}$ is assigned steadily increasing values. Forty-five such cases were analyzed, each case being one combination of the three parameters: symmetric performance specification Iimits $\left(k_{1}=k_{2}\right)$; systematic measurement error $\left(\mu_{\varepsilon}\right)$; and test tolerance adjustment (TA). The values used for these parameters are presented in table 3.5 , along with the set of nine $\sigma_{\varepsilon}$ values used to analyze each case. As for all of the cases analyzed in this section, the value of $\sigma_{u}$ is assumed to be unity. 
Partial results of this analysis are shown in the plots of figures $B .7$ through

B.12 of appendix B for those cases in which the performance specification

limits equal two standard deviations of $u\left(i . e ., k_{1}=k_{2}=2\right)$. Both the general pattern and the size of the effects of $\sigma_{\varepsilon}$ on CL and PL are illustrated here with one set of these plots.

Table 3.5 Parameter Values and Standard Deviation of Measurement Error Values Used to Analyze the Pattern and Magnitude of the Effect of the Standard Deviation of Measurement Error on $\mathrm{CL}$ and $\mathrm{PL}$.

Characteristic

Performance

Specification

Systematic

Measurement Error

Tolerance

Adjustment
Symbol

$k_{1}=k_{2}$

$\mu_{\varepsilon}$

TA
Values

$1,2,3$

$0,0.25,0.50$

$0,0.25,0.50,0.75,1.0$
Standard

Deviation of

Measurement

Error $\sigma_{\varepsilon}$

$0.1,0.2,0.3,0.4,0.5,0.6,0.7$, $0.8,0.9$ 
Figure 3.6 presents plots of the value of CL as a function of the standard deviation of measurement error for the case of systematic error equal to 0.25 . To analyze the effect that TA has on CL, four separate plots are given, based on the values specified for TA in table 3.5 .1 For all of these plots in figure 3.6 the condition in expression (3.8) is fulfilled, so that CL is a positively sloped function of $\sigma_{\varepsilon}$.

The curvature of all the plots in figure 3.6 varies depending on the value of TA and the range of interest for $\sigma_{\varepsilon}$. For high values of TA (i.e., $\geq$ 0.5) the plots are somewhat concave upward initially and then reach inflection points and become concave downward as $\sigma_{\varepsilon}$ increases. The points of inflection occur at lower values of $\sigma_{\varepsilon}$, the lower the value of TA used. Indeed, for the lowest value of TA (i.e., 0.25), the inflection point appears to occur for values of $\sigma_{\varepsilon}$ less than 0.1 . The significance of upward concavity is that the impacts of increases in $\sigma_{\varepsilon}$ on $\mathrm{CL}$ tend to increase with greater $\sigma_{\varepsilon}$. For example, the computed values underlying the plot for a TA value of 1.0 indicate that CL increases from 0.000200 to 0.000595 to 0.001200 when $\sigma_{\varepsilon}$ increases from 0.4 to 0.5 to 0.6 , respectively. Thus, the first increment is only 0.000395 (i.e., $0.000595-0.000200$ ), while the second increment is 0.000605

In contrast to this observed upward curvature, for $\sigma_{\varepsilon}$ values in excess of 0.6 , a general pattern of approximate linearity is observed for all of the plots. In this range, therefore, the impact on CL of increasing $\sigma_{\varepsilon}$ is relatively constant.

I Only four of the five values of TA given in table 3.5 are used in these plots because for $T A=0$ the condition given in expression (3.8) is violated (i.e., $\left.\mu_{\varepsilon}=0.25>T A=0\right)$. The plot of $C L$ for this value of $T A$ would have a negative slope. 


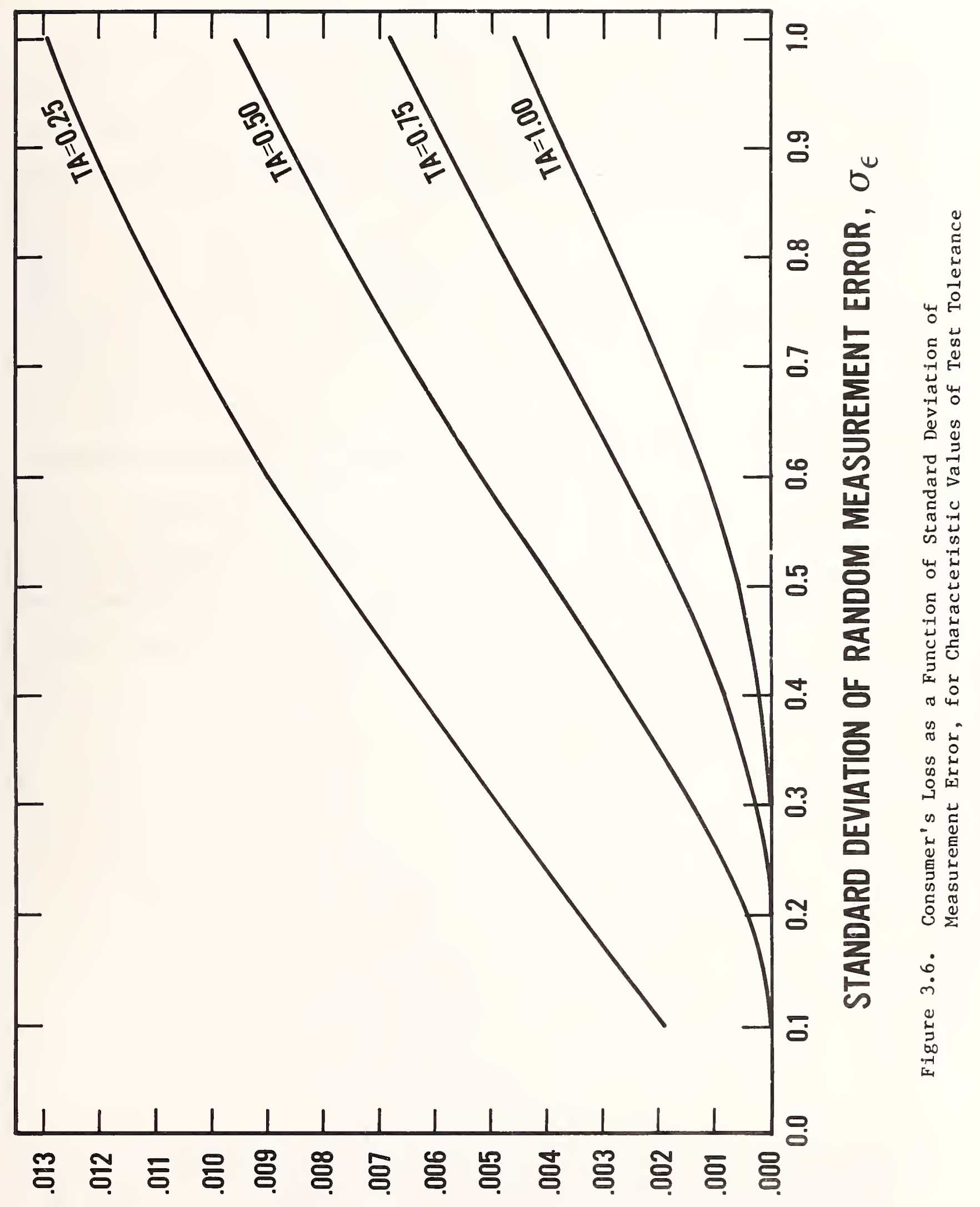

SSOT YבWกSNOJ 
Figure 3.7 presents the four plots of PL as a function of the standard deviation of measurement error for the same values of TA as used in figure 3.6 for CL. Because the condition specified in expression (3.9) is fulfilled for all the cases represented by these plots, they are positively sloped throughout their range.

The curvature of all the plots in figure 3.7 is such that they are concave upward over the entire range of $\sigma_{\varepsilon}$ values analyzed. Since it is unlikely that $\sigma_{\varepsilon}$ would exceed unity (the value of $\sigma_{u}$ ), this concavity can be said to prevail for most realistic test situations. 1 As is true for the effects on CL discussed above, the upward concavity means that the impacts of increases in $\sigma_{\varepsilon}$ on CL tend to increase with greater $\sigma_{\varepsilon}$. For example, the computed values underlying figure 3.7 indicate that for a TA value of 0.25 , CL increases from 0.047473 to 0.053500 to 0.062408 when $\sigma_{\varepsilon}$ increases from 0.1 to 0.2 to 0.3 , respectively. Thus, the first increment is only 0.006027 , while the next increment is 0.008908 .

$1^{1}$ The curvature of these plots where $\sigma_{\varepsilon}<0.1 \sigma_{u}$ was not analyzed here. Extrapolation of these plots back toward the origin would suggest that the curvature decreases with decreasing slope. 


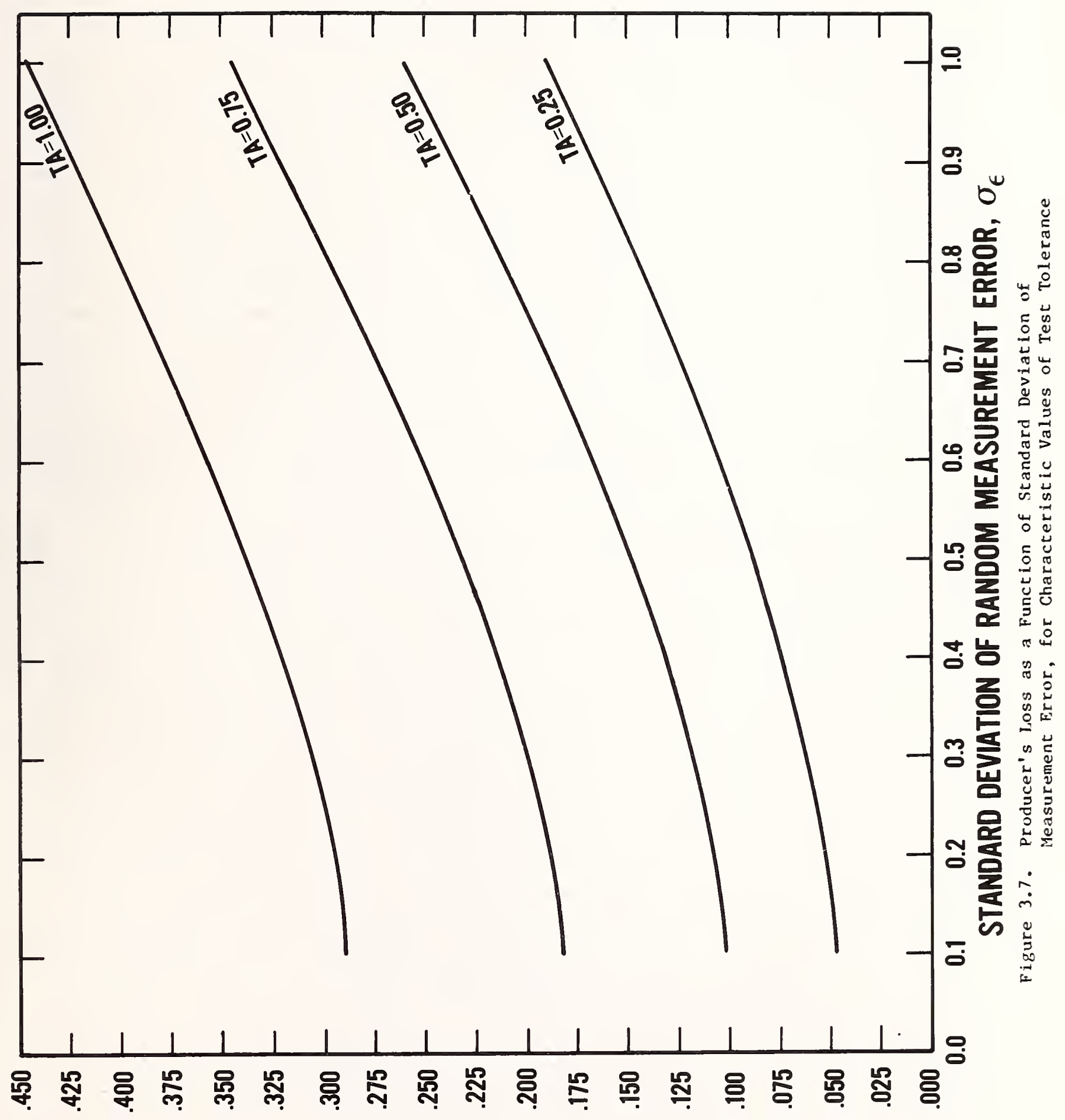

SSOT y3OnOOYd 


\section{Summary and Application}

In this report an economic model has been presented which traces the effects of alternative levels of accuracy in testing and measurement on the correctness of acceptance and rejection decisions. The model expresses two probabilities, that of accepting a bad unit (CL), and that of rejecting a good unit (PL), as explicit functions of systematic measurement error $\left(\mu_{\varepsilon}\right)$ and the standard deviation of random measurement error $\left(\sigma_{\varepsilon}\right)$. These functions can be used to calculate directly the benefits, as measured by lower probabilities of errors, from reduced systematic and/or random errors. When applied to a case study, an economic value, in terms of dollars saved per time period, can be established for these reduced probabilities. The economic value depends on the number of tests conducted in a time period and on the particular test situation being analyzed. Multiplication of each probability reduction by the number of items to be tested gives the expected reduction in the number of occurrences of each type of test error. The economic value of each reduced error occurrence can then be determined by identifying and categorizing the cost consequences of single CL and PL occurrences. Separate estimates of the value of each cost consequence have to be derived. Examples of such cost consequences for a CL occurrence are field repair costs, accidents due to equipment failure, and possible effects on readiness and mission success rates in military applications. Examples of cost implications for a PL occurrence are unnecessary diagnostic and repair costs, the costs of unnecessary retesting (including packing and shipping to higher echelon laboratories), excessive inventory of parts and UUTs because of downtime, and reduced production yields. 
The applicability as well as the dollar value of each of these and the many other cost implications resulting from occurrences of CL and PL can vary greatly depending on the particular test situation being analyzed. Examples of the many test applications possible are production testing both at intermediate stages and at the final product stage (i.e., outgoing tests), incoming testing of components to be used in manufacturing, and maintenance testing. The economic model presented in this report can be used to analyze all of these test applications, provided the basic nature of the measurement process is analog rather than digital. That is, the principal characteristic of the UUT that is being measured must be a continuous variable, rather than a binomial or other type of discrete variable. This requirement is not too restrictive, however, because even when semiconductor devices that are primarily digital in design are being tested, some critical analog measurements must be made.

This economic model can be applied to a wide variety of fields, including metrology, research planning, maintenance and procurement policy, and product quality assurance functions. To illustrate metrology research applications, the magnitudes of the reductions in CL and PL that would result from alternative calibration support strategies can be computed by the model and then used to assist program managers in selecting test methods and calibration support systems that have the highest potential payoff. In the maintenance area, the model can be used to optimize the frequency and quality of calibration procedures with existing test equipment. In the area of procurement policy, the model can be used to select the best new test equipment through a comparison of additional costs with the economic benefits of expected accuracy improvements. In quality assurance, the model can be applied to determine, for a particular product and test environment, which test specifications optimize the economic tradeoff between CL and PL. 


\section{Bibliography}

1. Be11, Barry A. and Petersons, Oskars, "ATE Calibration by Means of Dynamic Transport Standards," Proceedings of Autotestcon 81: International Automatic Testing Conference (Orlando, FL, October 19-21, 1981), Institute of Electrical and Electronic Engineers (IEEE Catalogue No. $81 \mathrm{CH} \mathrm{1716-0),} \mathrm{1981,}$ pp. 280-287.

2. Brady, Dale D. and Odorizzi, Dominick J., "Statistical Tolerancing of Complex Systems," Electronic Design, January 4, 1978, pp. 134-138.

3. Burr, I. W., "Specifying the Desired Distribution Rather than Maximum and Minimum Limits," Industrial Quality Contro1, Vo1. 24, No. 2, August 1967 , pp. $94 \mathrm{ff}$.

4. Crow, E. L., "Optimum Allocation of Calibration Errors," Industrial Quality Control, Vol. 23, No. 5, November 1966, pp. 215-218.

5. Eagle, A. R., "A Method for Handling Errors in Testing and Measuring," Industrial Quality Control, Vol. 10, No. 5, March 1954, pp. 10-15.

6. Eisenhart, Churchill, "Realistic Evaluation of the Precision and Accuracy of Instrument Calibration Systems," Journal of Research of the National Bureau of Standards, Vol. 67C, No. 2, April-June 1963.

7. Evans, D. H., "Optimum Tolerance Assignment to Yield Minimum Manufacturing Cost," Bel1 System Technical Journal, Vol. 37, No. 2, 1958.

8. Evans, D. H., "A Statistical Tolerancing Formulation," Journal of Quality Technology, Vol. 2, No. 4, October 1970, pp. $226 \mathrm{ff}$.

9. Evans, D. H., "An Application of Numerical Integration Techniques to Statistical Tolerancing, II--A Note on the Error," Technometrics, Vol. 13, No. 2, May, 1971, pp. $315 \mathrm{ff}$.

10. Evans, D. H., "An Application of Numerical Integration Techniques to Statistical Tolerancing, III--General Distributions," Technometrics, Vol. 14, No. 1, February 1972, pp. $23 \mathrm{ff}$.

11. Evans, D. H., "Statistical Tolerancing: The State of the Art (Part I. Background)," Journal of Quality Technology, Vo1. 6, No. 4, October 1974 , pp. 188-195.

12. Evans, D. H., "Statistical Tolerancing: The State of the Art (Part II. Methods for Estimating Moments)," Journal of Quality Technology, Vol. 7, No. 1, January 1975, pp. 1-12.

13. Evans, D. H., "Statistical Tolerancing: The State of the Art (Part III. Shifts and Drifts)," Journal of Quality Technology, Vol. 7, No. 2, April 1975, pp. 72-76. 
14. Glassman, Jerry and Rodriduez, Robert N., "Treatment of Errors in Measurement Systems," (Mimeo, Navy Metrology Englneering Center, Pomona, CA).

15. Grubbs, F. E., "Errors of Measurement, Precision, Accuracy, and the Statistical Comparison of Measuring Instruments," Technometrics, Vol. 15, No. 1, February 1973, pp. 53-66.

16. Grubbs, F. E., "On Estimating Precision of Measuring Instruments and Product Variability," Journal of the American Statistical Association, Vol. 43, No. 242, June 1948, pp. 243-264.

17. Grubbs, Frank E. and Coon, Helen J., "On Setting Test Limits Relative to Specification Limits," Industrial Quality Control, March 1954, pp. 15-20.

18. Hilliard, Jimmy E. and Miller, J. R., III, "The Effect of Calibration and End Item Performance in Echelon Systems," Journal of Quality Technology, Vol. 12, No. 2, April 1980, pp. 61-70.

19. Juran, J. M., Editor, Quality Control Handbook, 2nd Edition, McGraw Hill, New York, New York, 1962 .

20. $\mathrm{Ku}$, Harry H., "Notes on the Use of Propagation of Error Formulas," Journal of Research of the National Bureau of Standards, Vol. 70C, No. 4, October-December 1966 .

21. Mansoor, E. M., "The Application of Probability to Tolerances Used in Engineering Design," Proceedings of the Institution of Mechanical Engineers, Vol. 1781, No. 1, 1963, pp. $29 \mathrm{ff}$.

22. McNish, A. G., and Cameron, J. M., "Propagation of Errors in a Chain of Standards," IRE Transactions on Instrumentation, Vol. I-9, No. 2, September 1960 , Pp. 101-104.

23. Miller, J. R., III, et al., "Effect of Calibration on End Item Performance," USAMCC-MM-75-15. U.S. Army Metrology and Calibration Center, Redstone Arsenal, Alabama, November 25, 1975.

24. Owen, D. B., "Applications of the Tables," Chapter II of Tables of the Bivariate Normal Distribution Function and Related Functions, National Bureau of Standards Applied Mathematics Series 50, U.S. Government Printing office, Washington, DC, June 1959.

25. Owen, D. B., and Wiesen, J. M., "A Method of Computing Bivariate Normal Probabilities with an Application to Handling Errors in Testing and Measuring," Bell System Technical Journal, March 1959, pp. 553-572.

26. Pike, E. W., and Silverberg, T. R., "Assigning Tolerances for Maximum Economy," Machine Design, September 1953, pp. 139-146. 
27. Rajaraman, M. K., "Allocation of Errors in Hierarchical Calibration or Assembly," Journal of Quality Technology, Vol . 6, No. 1, January 1974, pp. 42-45.

28. Tingey, F。 H. and Merrill, J. A., "Minimum Risk Specification Limits," AEC Research and Development Report IDO-16396 (Phillips Petroleum Co., Atomic Energy Division, Contract No. AT (10-1)-205), July 30, 1957.

29. Woods, W. M. and Zerna, P. W., "Cumulative Effect of Calibration Errors," Industrial Quality Control, Vo1. 22, No. 8, February 1966, pp. 411-412. 


\section{Appendix A. Binormal.CL-PL, an Interactive Computer Program for Calculating Consumer's Loss and Producer's Loss in Testing}

\section{A.1 Purpose}

BINORMAL.CL-PL is an interactive FORTRAN program developed for use in measuring the benefits of improved accuracy of test equipment.1 Two types of accuracy improvements can be analyzed: (1) a reduction of the systematic measurement error of test equipment (i.e., a reduction of the bias present in the measurement results); and (2) a reduction of the standard deviation of the measurement error of the test equipment (i.e., an increase in measurement precision). These improvements might be achieved, for example, through better test operating procedures, more controlled environmental conditions during testing, more frequent calibration procedures, as well as through the acquisition of more accurate test equipment. When provided with parameters that fully characterize the distribution of the UUT performance ${ }^{2}$ and the accuracy of the test equipment, BINORMAL.CL-PL calculates the probability of accepting a UUT that does not conform to its performance specifications (i.e., Consumer's Loss or CL) and the probability of rejecting a UUT that does conform to its performance specifications (i.e., Producer's Loss or PL). The option is available for conducting a sensitivity analysis of the results by

${ }^{1}$ The software documentation in this appendix follows the principal Federal Information Processing Standards (FIPS) found in Guidelines for Documentation of Computer Programs and Automated Data Systems, FIPS Publication \$38, U.S. Department of Commerce, National Bureau of Standards, February 15, 1976.

2 UUT performance refers to the value of the particular UUT attribute that is being measured by the test equipment. 
varying the parameters relating to the accuracy of the test equipment and the setting of the test specifications.

BINORMAL。CL-PL can be helpful in planning research, making maintenance and procurement decisions, and solving certain quality control problems. The results of the program can be used to guide decisions regarding which test methods and calibration support strategies would have the highest payoff. The program also could be used to optimize the frequency and quality of calibration procedures with existing test equipment, as well as to select new test equipment by comparing additional costs with expected accuracy improvements. Finally, in the area of quality control, the sensitivity analysis capability of the program can be used to establish for a particular product the test specifications that optimize the trade-off between CL and PL。

\section{A.2 Scope}

BINORMAL.CL-PL can be run on any computer with a FORTRAN 77 compilerl and access to routines supplied by the International Mathematical and Statistical Libraries, Inc. (IMSL).2 The program is quite flexible in a number of ways. In the first place, it can be applied to the three most commonly encountered test situations: two-tail tests; upper-tail tests; and lower-tail tests.3 In a two-tall test, the UUT performance is expected to be between established

${ }^{1}$ American National Standards Programming Language, FORTRAN, ANSI X3.9-1978.

2 Documentation for the two routines used in the program, MDNOR and MDBNOR, can be found in International Mathematical and Statistical Libraries, Inc., The IMSL Library, 9th Edition, Vol. 3 (Houston, TX, 1982).

${ }^{3}$ The only test situations that cannot be analyzed by the program are those in which the acceptable values are in any way separated from one another by unacceptable values. For instance, if the extreme values (i.e., the two tails) of the UUT performance distribution constituted acceptable regions while the values close to the mean constituted the unacceptable region, then this program could not be used. 
upper and lower performance specifications in order to be acceptable. An upper-tail test is one in which the UUT performance is expected to be below a given upper performance specification to be acceptable, while a lower-tail test is one in which the UUT performance is expected to be above a lower performance specification to be acceptable. The program is also flexible in that the test specifications, that is, the cut-off values for the measured UUT performance, can be set anywhere in relation to the performance specifications. Moreover, when the program is used for a two-tail test, the performance specifications need not be symmetric around the mean UUT performance. There is also great flexibility in the types of UUTs and test equipment the program can analyze. The only requirement is that the UUT performance and the test equipment measurement error both must be assumed to follow normal distributions, which implies that they can be treated as continuous variables. The program user is free to specify any means and standard deviations for these normal distributions. 1

\section{A.3 Using the Program}

Once the user has entered the proper control statements to begin execution of the program, 2 the computer prompts the user for each input value to be entered. Table A.1 lists and defines the symbols used for the input variables in this appendix and in the program. In addition to entering these values, the user must indicate whether the test has two tails, an upper tail only, or a lower tail only.

${ }^{1}$ In practice, the standard deviation of the measurement error will typically be less than that of the UUT.

${ }^{2}$ Since control statements are specific to the computer system on which the program is run, they will not be discussed here. 
The output of the program is a listing of all the input values and the corresponding computed probabilities, CL and PL. After the results are printed the user indicates whether or not a sensitivity analysis is desired. If not, the program ends. If sensitivity analysis is requested, the user is prompted to enter new values for $M E, S D E$, and $B U$ and/or $B L$ (depending on the test situation). New values for $C L$ and $P L$ are calculated and the new results are printed in the same format as before. The user can continue entering new values as many times as desired. A sample run with one case of sensitivity analysis is shown in figure A.1.

Table A.1 Input Variables for BINORMAL.CL-PL

Symbol

Definition

MU

SDU

ME

SDE

SU

SL

BU

BL
Mean of the UUT performance distribution.

Standard deviation of the UUT performance distribution.

Mean of the test equipment measurement error distribution, also known as undetected systematic measurement error or bias.

Standard deviation of the test equipment measurement error distribution, also known as measurement imprecision.

Upper specification limit for UUT performance.

Lower specification limit for UUT performance.

Upper test equipment tolerance factor.1

Lower test equipment tolerance factor.1

1 The tolerance factor is the number of SDEs between the UUT performance specification value and the test specification value. It is generally used to allow for measurement error of the test equipment. A positive factor means that the test specification limits are more stringent (i.e., more likely to reject UUTs) than the unadjusted performance specification limits. In many cases the tolerance factor is zero, which means that the test specification limits are set equal to the UUT performance specification limits. 
Figure A.1. Illustrative Computer Run of BINORMAL.CL-PL

ENTER MEAN OF MEASUREMENT ERROR

$>.25$

ENTER STANDARD DEVIATION OF MEASUREMENT ERROR

$>.5$

ENTER MEAN OF TRUE ?ERFORMANCE

$>0$

ENTER STANDARD DEVIATION OF TRUE PERFORMANCE

$>1$

IS THIS A TWO-TAIL TEST OF PERFORMANCE?(Y/N)

$>Y$

ENTER UPPER PERFORMANCE SPECIFICATION

$>2$

ENTER LOWFR PERFORMANCE SPECIFICATION

$>-2$

ENTER UPPER TOLERANCE FACTOR OF ATE

$>1$

ENTER LOWER TOLERANCE FACTOR OF ATE

$>1$

FOR :

MEAN OF MEASUREMENT ERROR $=.25000000$

STANDARD DEVIATION OF MEASUREMENT ERROR $=.50000000$

MEAN OF TRUE PERFORMANCE $=.00000000$

STANIARD DEVIATION OF TRUE PERFORMANCE $=1.0000000$

UPPER PERFORMANCE SPECIF ICATINN $=2.0000000$

LOWER PERFORMANCE SPECIFICATION $=-2.0000000$

UPPER TOLERANCE FACTOR OF ATE $=1.0000000$

LOWER TOLERANCE. FACTOR OF ATE $=1.0000000$

THEN CONSUMER LOSS $=\quad .003878$

AND PRODUCER LOSS $=\quad .149917$

WOULD YOU LIKE TO DO A SENSITIVITY ANALYSIS?(Y/N)

$>Y$

ENTER NEW VALUES FOR MEAN OF MEASIJREMENT FRROR

STANDARD DEVIATION OF MEASIJPEMENT FRROR ,UPPER TOLERANCF. FACTOR OF ATE, AND LOWER TOLERANCE FACTOR OF ATE , ONE VALIJE PER PROMPT.

$>.125$

$>.5$

$>1$

$>1$

FOR :

MEAN OF MEASIIREMENT ERROR $=.12500000$

STANDARD DEVIATION OF MEASUREMENT ERROR $=.50000000$

MEAN OF TRUE PERFORMANCE. $=.00000000$

STANDARD DEYIATION OF TRUE PERFORMANCE $=1.0000000$

UPPER PERFORMANCE SPECIFICATION $=2.0000000$

LOWER PERFORMANCE SPECIFICATION $=-2.0000000$

UPPER TOLERANCE FACTOR DF ATE $=1.0000000$

LOWER TOLFRANCE FACTOR OF ATE $=1.0000000$

THEN CONSUAER LOSS $=\quad .003214$

AND PRODIJCER LOSS = $\quad .140143$

WOULD YOU LIKE TO DO A SENSITIVITY ANALYSIS? $(Y / N)$

$>\mathrm{N}$ 
The user should be aware that there is no capability in the program for evaluating whether the numbers entered are reasonable. That is, there is no edit checking in the program. Thus, the user must be sure that the values entered represent a realistic situation. For example, if the values entered produce a lower test specification that is greater than the upper test specification, then the program will not fail to run, but may result in negative values for $\mathrm{CL}$ and/or values for PL that are greater than unity. A.4 Program Characteristics

BINORMAL.CL-PL is written in FORTRAN 77 with external routines supplied by IMSL. These routines, MDNOR and MDBNOR, give single precision results. The accuracy of MDNOR, which calculates univariate normal probabilities, is dependent on the computer system being used. To compute the CL and PL values presented as illustrations and results throughout this report, the authors employed the UNIVAC $1100 / 82$ system installed at NBS in Gaithersburg, Maryland. The routine MDNOR would be accurate to the eighth digit on such a 36 bit machine. 1 Documentation in the IMSL Library states that MDBNOR, which calculates bivariate normal probabilities, gives values differing by less than 0.00001 from the values in Tables of the Bivariate Normal Distribution Function and Related Functions. 2 The values in these tables have a maximum absolute error of $0.000002,3$ so that the total absolute error for each bivariate normal probability computed by MDBNOR is less than 0.000012 . Given these accuracies for the two external routines used, it is expected that the value of $\mathrm{CL}$

${ }^{1}$ Telephone conversation with technical staff at IMSL.

${ }^{2}$ U.S. Department of Commerce, Tables of the Bivariate Normal Distribution Function and Related Functions, National Bureau of Standards, Applied Mathematics Series 50 (Washington, D.C., 1959).

${ }^{3}$ Ibid., p. vi. 
computed by BINORMAL.CL-PL will have a maximum alsolute error of 0.000048 , while the value of PL would have a maximum absolute error of 0.00004804 . The following formulas are used to calculate CL and PL:

$$
\begin{aligned}
& \mathrm{RHO}=\frac{\mathrm{SDU}}{\sqrt{\mathrm{SDU}^{2}+\mathrm{SDE}^{2}}} ; \begin{array}{l}
\text { where RHO is the statistical correlation } \\
\text { between the UUT performance values and the } \\
\text { observed measurement values; }
\end{array} \\
& \mathrm{K} 1=\frac{\mathrm{SU}-\mathrm{MU} ;}{\mathrm{SDU}} \\
& \mathrm{K} 2=\frac{\mathrm{MU}-\mathrm{SL} ;}{\mathrm{SDU}} \\
& \mathrm{Q}=\frac{\mathrm{SU}-\mathrm{MU}-\left(\mathrm{BU}^{*} \mathrm{SDE}\right)-\mathrm{ME}}{\mathrm{SDU}} ; \text { and } \\
& \mathrm{Q} 2=\frac{\left.\mathrm{MU}-\mathrm{SL}^{2}-\mathrm{BL}^{*} \mathrm{SDE}\right)+\mathrm{ME}}{}
\end{aligned}
$$

For a two-tail test,

$$
\mathrm{CL}=\mathrm{L}(-\mathrm{K} 1, \mathrm{Q} 2, \mathrm{RHO})-\mathrm{L}(-\mathrm{K} 1,-\mathrm{Q} 1, \mathrm{RHO})-\mathrm{L}(-\mathrm{K} 2,-\mathrm{Q} 2, \mathrm{RHO})+\mathrm{L}(-\mathrm{K} 2, \mathrm{Q} 1, \mathrm{RHO}) \text {, }
$$

where $L(x, y, r)$ is the joint probability that $X<x$ and $Y<y$ given that $(X, Y)$ is the standardized bivariate normal cumulative distribution function with correlation RHO between $\mathrm{X}$ and $\mathrm{Y}$, as calculated by MDBNOR; and

$$
P L=C L+G(K 1)+G(K 2)-G(Q 1)-G(Q 2),
$$

where $G(x)$ is the probability that $X<x$ given that $X$ is the standardized univariate normal cumulative distribution function, as calculated by MDNOR.

For an upper-tail test,

$$
\begin{aligned}
& \mathrm{CL}=\mathrm{G}(-\mathrm{Kl})-\mathrm{L}(-\mathrm{K} 1,-\mathrm{Q} 1, \mathrm{RHO}) \text { and } \\
& \mathrm{PL}=\mathrm{G}(-\mathrm{Ql})-\mathrm{L}(-\mathrm{K} 1,-\mathrm{Ql}, \mathrm{RHO})
\end{aligned}
$$

For a lower-tail test,

$$
\begin{aligned}
& \mathrm{CL}=\mathrm{G}(-\mathrm{K} 2)-\mathrm{L}(-\mathrm{K} 2,-\mathrm{Q} 2, \mathrm{RHO}) \text { and } \\
& \mathrm{PL}=\mathrm{G}(-\mathrm{Q} 2)-\mathrm{L}(-\mathrm{K} 2,-\mathrm{Q} 2, \mathrm{RHO})
\end{aligned}
$$

A listing of BINORMAL.CL-PL is shown in figure A.2. 
Figure A.2. Computer Code Listing of BINORMAL.CL-PL

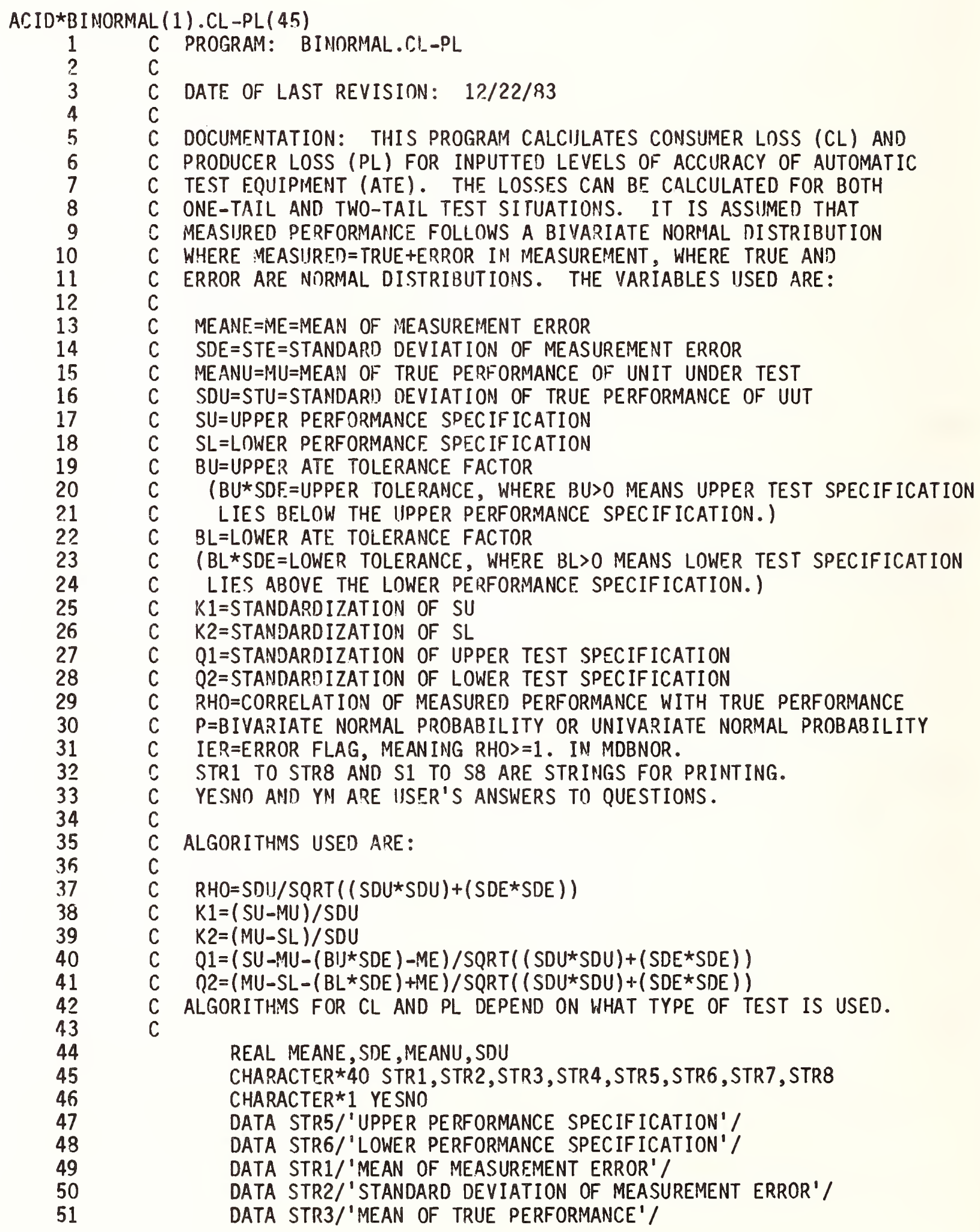


DATA STR4/'STANDARD DEVIATION OF TRUE PERFORMAMCE' /

C DATA STR8/'LOWER TOLERANCE FACTOR OF ATE'/

C

C DETERMINE WHAT TYPE OF TEST IS DONE AND CALL APPROPRIATE

C SUBROUTINE. IJPPER-TAIL MEANIS ONLY TRUE PERFORMANCE BELOW

C SOME VALUE $X$ IS ACCEPTABLE. LOWER-TAIL MEANS ONLY PERFORMANCE

C ABOVE VALUIE $Y$ IS ACCEPTABLE. TWO-TAIL MEANS ONLY PERFORMANCE

C BETHEEN VALUES $X$ AND $Y$ IS ACCEPTABLE.

C

2000 FORMAT ( ${ }^{\prime}$ IS THIS A TWO-TAIL TEST OF PERFORMANCE?(Y/N)' $)$ $\operatorname{READ}(5,1000)$ YESNO

1000 FORMAT(A1)

IF (YESNO.EQ. ' $Y$ ') CALL CLPL2(MEANE, SDE, MEANU, SDI, STR1, STR2,

+ STR3, STR4, STR5, STR6, STR7, STR8) $\operatorname{WRITE}(6,2010)$

2010 FORMAT( ' IS THIS AN UPPER-TAIL TEST?(Y/N)')

$\operatorname{READ}(5,1000)$ YESNO

IF (YESNO.ER.' 'Y') CALL CLPLIJP(MEANE, SDE, MEANU, SDU, STR1, STR2,

+ STR3,STR4,STR5,STR7)

IF (YESNO.EQ.' 'N') CALL CLPLOW(MEANE, SDE, MEANU, SDII, STR1, STR2,

+ STR3, STR4, STR6, STR8) STOP

END

C

C C

C

C

INPUT IJPPER AND LOWER LIMITS AND TOLERANCE FACTORS.

CALL INPUT(SU,S5)

CALL INPIIT(SL, S6)

CALL INPUT (BU,S7)

CALL INPUT(BL,S8)

C

$c$

REAL SU, SL , ME, MU, STE, STU, BU, BL, RHO , K1 , K2 , K3 , K4 , P1 , P2 , P3 , P4

REAL $Q 1, Q 2,03,04, C L, P L$

INTEGER IER

CHARACTER $* 40 \mathrm{~S} 1, \mathrm{~S} 2, \mathrm{~S} 3, \mathrm{S4}, \mathrm{S} 5, \mathrm{S6}, \mathrm{S7}, \mathrm{S} 8$

CHARACTER $\star 1$ YN

C

CALCULATE NeEDED VALUES. RHO/STU $=1 / S Q R T((S T U \star \star 2)+(S T E \star \star 2))$

RHO $=S T U / S Q R T((S T U * S T U)+(S T E * S T E))$

$K 1=(S U-M U) / S T U$

$K 2=(M U-S L) / S T U$

$K 3=-K 1$

$K 4=-K 2$ 
$Q 1=(S U-M U-(B U * S T E)-M E) * R H O / S T U$

$Q 2=(: M U-S L-(B L * S T E)+M E) * R H O / S T U$

$Q 3=-21$

$Q 4=-Q 2$

CALL MDBNOR ( $K 3,22, R H 0, P 1, I E R)$

CALL MDBNOR(K3,Q3, RHO,P2, IER)

CALL MDBNOR(K4, $\mathrm{Q} 4, \mathrm{RHO}, \mathrm{P} 3$, IER)

CALL MNBNOR $(X 4,21, \mathrm{RHO}, \mathrm{P4}$, IER)

$C L=P 1-P 2-P 3+P 4$

CALL MDNOR $(K 1, P 1)$

CALL MDNOR $(K 2, P 2)$

CALL MDNOR $(01, P .3)$

CALL MDNOR $(Q 2, P 4)$

$P L=C L+P 1+P 2-P 3-P A$

C

C WRITE RESIJLTS.

C

WRITE $(6,2100)$ S1, ME , S2, STE, S.3, MU, S4, STU, S5, SU, S6, SL , S7 , BIJ,

$+\mathrm{S} 8, \mathrm{BL}, \mathrm{CL}, \mathrm{PL}$

2100 FORMAT(' FOR:', /,8(1X,A40,' $=$ ',G15.8,/)/,5X, 'THEN ', + 'CONSUMER LOSS $=$, F10.6, $/, 5 X^{\prime}, 1$ AND PRODUCER LOSS'

C$$
+1=\quad, \text { F } 10.6 \text { ) }
$$

c OPPORTUNITY FOR SENSITIVITY ANALYSIS.

C

$\operatorname{WRITE}(6,2110)$

2110 FORMAT (' WOULD YOU LIKE TO DO A SENSITIVITY ANALYSIS?(Y/N)') $\operatorname{READ}(5,1100) Y N$

1100 FORMAT(A1)

IF (YN . NE.' 'Y') STOP

WRITE $(6,2120)$ S1,S2,S7,S8

2120 FORMAT(' ENTER NEW VALUES FOR ', A40, ' $, 1, /, 1 \times, A 40,1,1$,A40, + ', AND $1, /, 1 \times$, A 40,, , ONE VALUE PER PROMPT. $\left.{ }^{\prime}\right)$ READ *, ME, STE, BU, BL GO TO 2

END

C

C

C

SUBROUTINE CLPLUP (ME, STE, MU, STU, S1, S2, S3, S4, S5, S7)

EXTERNAL MDNOR, MDBNOR

REAL ME, STE,MU, STU, BU, SU, RHO , K1, K3, P1 , P2, Q1, R3, CL, PL INTEGER IER

CHARACTFR $* 40 \mathrm{S1}, \mathrm{S2}, \mathrm{S3}, \mathrm{S4}, \mathrm{S5}, \mathrm{S7}$

CHARACTER ${ }^{*}$ YN

C

C INPUT UPPER LIMIT AND TOLERANCE FACTOR.

C

CALL INPUT (SU,S5)

CALL INPUT(BU,S7)

C

C CALCIILATE NEEDED VALUES.

C

$3 \quad R H O=S T U / S Q R T((S T U * S T U)+(S T E \star S T E))$

$K 1=(S U-M I I) / S T U$

$K 3=-K 1$

$Q 1=(S U-M U-(B U \star S T E)-M E) \star R H O / S T U$

$Q 3=-Q 1$

CALL MDBNOR $(K 3, \cap 3, \mathrm{RHO}, \mathrm{P} 1$, IER $)$

CALL MDNOR $(K 3, P 2)$ 
C

C WRITE RESULTS.

C

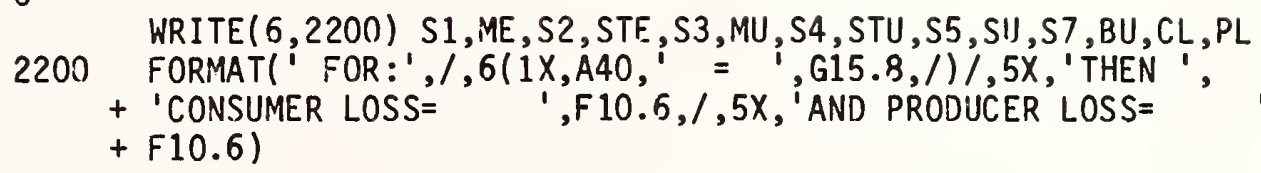


C 
Appendix B. Plots of Consumer's Loss and Producer's Loss as Functions of the Mean and Standard Deviation of Measurement Error

\section{B.1 Int roduction}

This appendix presents plots illustrating the effects of changes in the mean and standard deviation of the measurement error of test equipment on Consumer's Loss (CL) and Producer's Loss (PL) when the distribution of UUT performance and the performance specifications are both held constant. These effects are shown for a range of alternative values of test specification tolerances. Examples are given of how to read and interpret the plots. These plots have the same general applications as the computer program which generated them, BINORMAL.CL-PL; however, they are somewhat less flexible than the program because the range of situations they cover is limited. Consequently, the graphs are most useful when approximations of CL and PL are adequate or when access to a computer that has BINORMAL.CL-PL installed is unavailable or limited. The algorithms used tc calculate CL and PL are not discussed in this appendix, but are given in appendix $A$ and explained in more depth in section 2. The notation used in this appendix is the same as used in the main body of the report and as defined in table 2.1 .

\section{B.2 Scope}

Steps were taken to ensure that the values used to generate CL and PL were reasonable and representative of values found in actual test equipment applications; however, because of space limitations not all conceivable applications are represented. For instance, the graphs show CL and PL for 
two-tail tests, but many applications call for one-tail tests. Similarly, all systematic measurement errors and tolerances used in these plots are non-negative, although these parameters can certainly assume negative values in actual test situations.

There are two restrictions common to all the figures in this appendix. The first is that the underlying UUT performance distribution is standard normal (i.e., $\mu_{u}=0, \sigma_{u}=1$ ). The second restriction is that the test is two-tailed with performance specifications and test specifications symmetric around $\mu_{\mathrm{u}}$ and performance specifications set at $S_{U}=-S_{L}=2 \sigma_{u}$. It is possible to make adjustments to any data set for which the UUT performance can be treated as nornal in order to satisfy the first restriction. The second restriction, however, must be strictly satisfied. To illustrate how these restrictions affect the applicability of the figures, suppose the following parameters describe a test situation: $\mu_{\mathrm{u}}=10, \sigma_{\mathrm{U}}=2, \mu_{\varepsilon}=4, \sigma_{\varepsilon}=1, \mathrm{~S}_{U}=$ 14, $\mathrm{S}_{\mathrm{L}}=6$, and $\mathrm{TA}=4$. The first step in adjusting the data to satisfy the first restriction is to standardize the UUT performance specifications and the mean UUT performance. Denoting the resulting adjusted parameters with an asterisk, we have $\mu_{\mathrm{u}}^{*}=(10-10) / 2=0, \mathrm{~S}_{\mathrm{U}^{*}}=(14-10) / 2=2$, and $\mathrm{S}_{\mathrm{L}}^{*}=(6-10) / 2=$ -2. Because $S_{U^{*}}=-S_{L^{*}}=2$ in this case and because the test specifications are symmetric at $\mathrm{TA}=4$, the second restriction is satisfied and it is possible to use the plots to analyze the situation. If this were not the case, BINORMAL.CL-PL would have to be used for the analysis. The next step in adjusting the parameters is to divide all remaining values by $\sigma_{\mathrm{u}}$ to convert them to the new scale. Thus, $\sigma_{u^{*}}=2 / 2=1, \sigma_{\varepsilon}{ }^{*}=1 / 2=.5, \mu_{\varepsilon} *=4 / 2=2$, and $\mathrm{TA}^{*}=4 / 2=2$. These values should be used to identify which plots are appropriate for analyzing the situation. 
B.3 Interpretation of the Plots

There are three figures showing the effect of systematic measurement error on CL (figures B.1, B.2, and B.3), and three showing its effect on PL (figures B.4, B.5, and B.6). The assumed standard deviation of the measurement error, $\sigma_{\varepsilon}$, is 0.5 in figures B.1 and B.4, 0.25 in figures B.2 and B.5, and 0.1 in figures $B .3$ and B.6. Other than this variation, all assumptions are the same for these six figures. There are also three figures showing the effect of the standard deviation of the measurement error on CL (figures B.7, B.8, and B.9) and three showing its effect on PL (figures B.10, B.11, and B.12). The assumed systematic measurement error is 0.5 in figures B.7 and B.10, 0.25 in figures B.8 and B.11, and 0.0 in figures B.9 and B.12. Other than this variation, all assumptions for these six figures are the same. For all twelve figures, several plots are given, each plot having a different assumed level of TA. This arrangement permits one to observe what effect TA has on CL and PL for the different situations. As was discussed in section 3, the value of TA has significant effects, but in opposite directions, on CL and PL. As can be observed in all the figures, a decrease in TA increases CL but decreases PL.

Note that the figures showing the effects of $\sigma_{\varepsilon}$ (i.e., figures B.7 through B.12) do not all have the same number of plots. As stated in expression (3.8) of section 3, when TA is smaller than the systematic measurement error, a decrease in $\sigma_{\varepsilon}$ does not always cause a decrease in CL. The plots included in the figures are restricted to those that represent 
situations where it is clearly advantageous to decrease $\mu_{\varepsilon}$ and $\sigma_{\varepsilon} \cdot 1$

Consequently, no plots were included in figures B.7 through B.9 to show the effect of $\sigma_{\varepsilon}$ on CL for cases in which TA is smaller than $\mu_{\varepsilon}$. Figures B.10 through B.12 show the effect of $\sigma_{\varepsilon}$ on $\mathrm{PL}$ for the same TA values used in figures B.7 through B.9.

FFor a discussion of this phenomenon and more information about the effect of $\mu_{\varepsilon}$ and $\sigma_{\varepsilon}$ on $C L$ and $P L$ in situations not covered by the figures, see section 3 . 


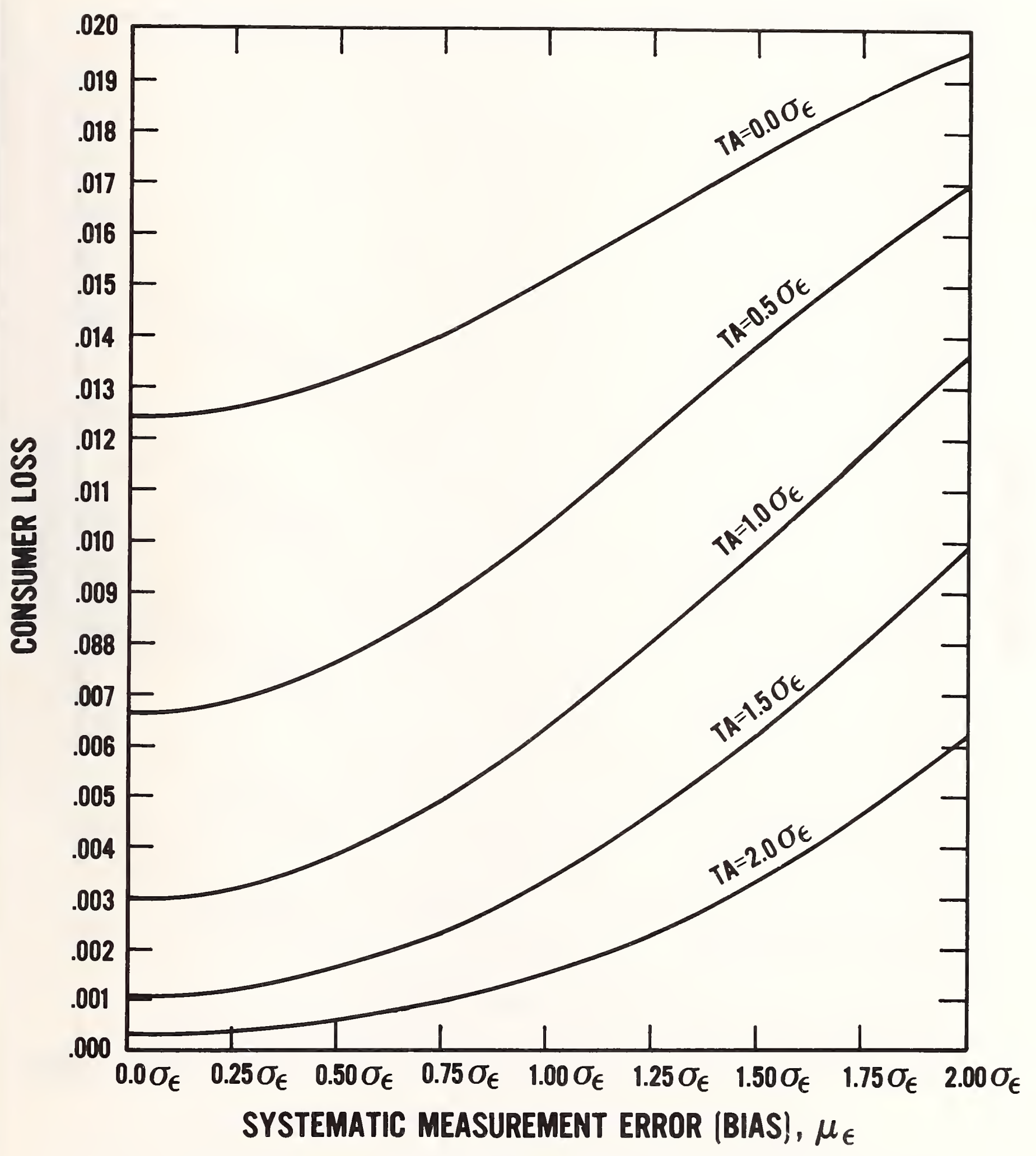

Figure B.1. Effect of Systematic Measurement Error on Consumer's Loss $\left(\sigma_{\varepsilon}=0.5, \mu_{u}=0, \sigma_{u}=1, s_{U}=2, s_{L}=-2\right)$ 


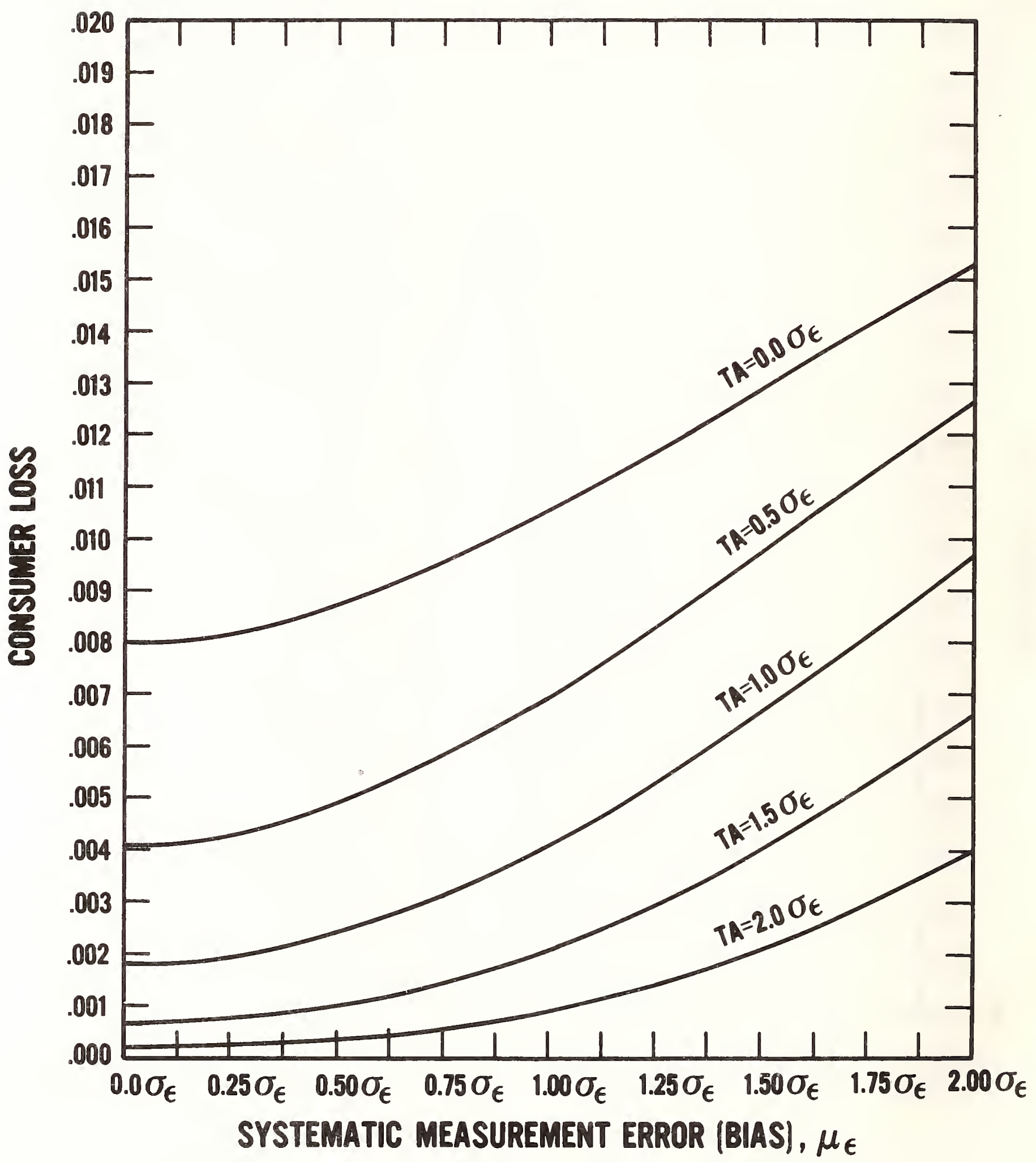

Figure B.2. Effect of Systematic Measurement Error on Consumer's Loss $\left(\sigma_{\varepsilon}=0.25, \mu_{\mathrm{u}}=0, \sigma_{\mathrm{u}}=1, S_{U}=2, S_{\mathrm{L}}=-2\right) \quad 67$ 


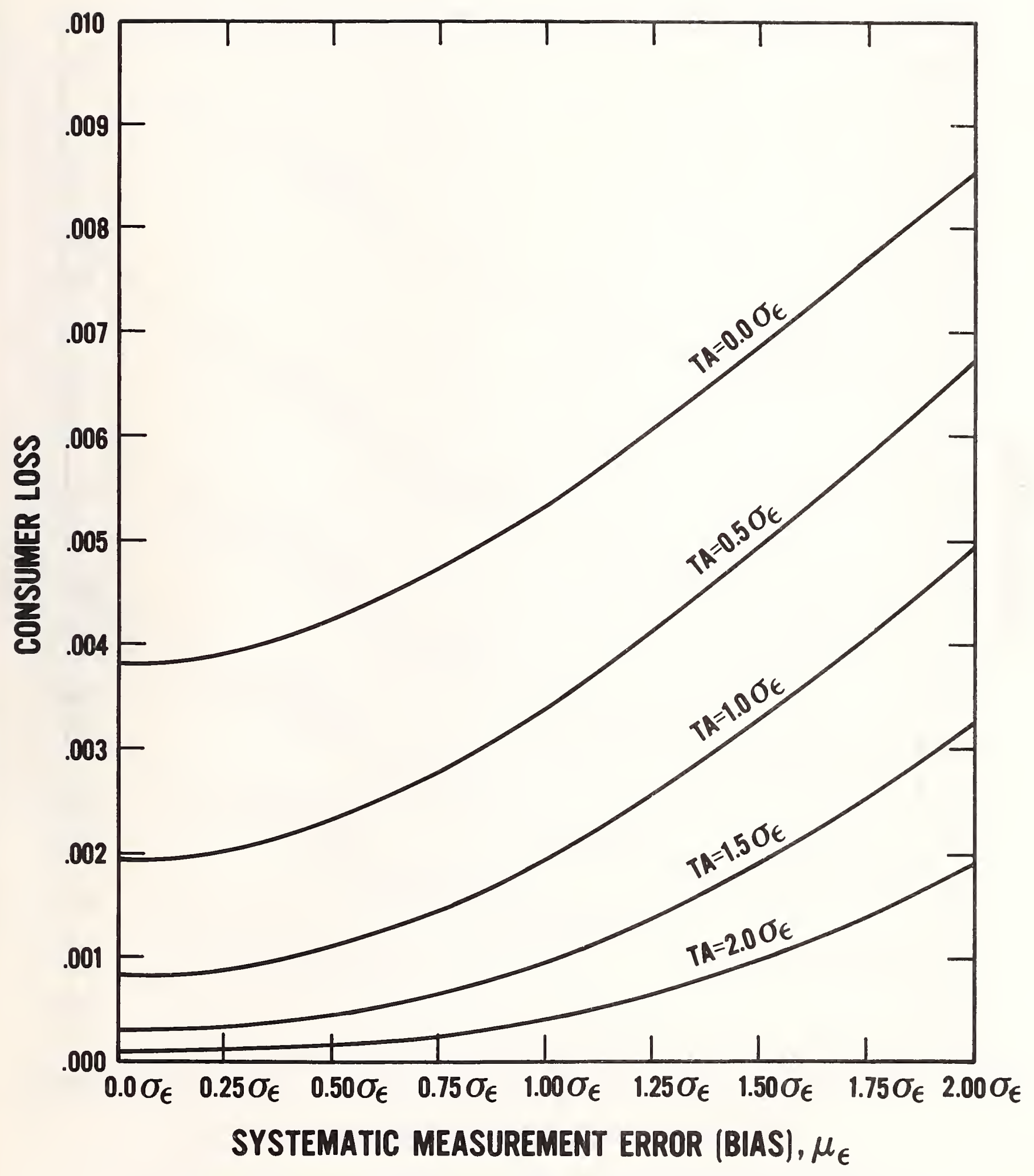

Figure B.3. Effect of Systematic Measurement Error on Consumer's Loss $\left(\sigma_{\varepsilon}=0.1, \mu_{\mathrm{u}}=0, \sigma_{\mathrm{u}}=1, \mathrm{~s}_{\mathrm{U}}=2, \mathrm{~s}_{\mathrm{L}}=-2\right)$ 


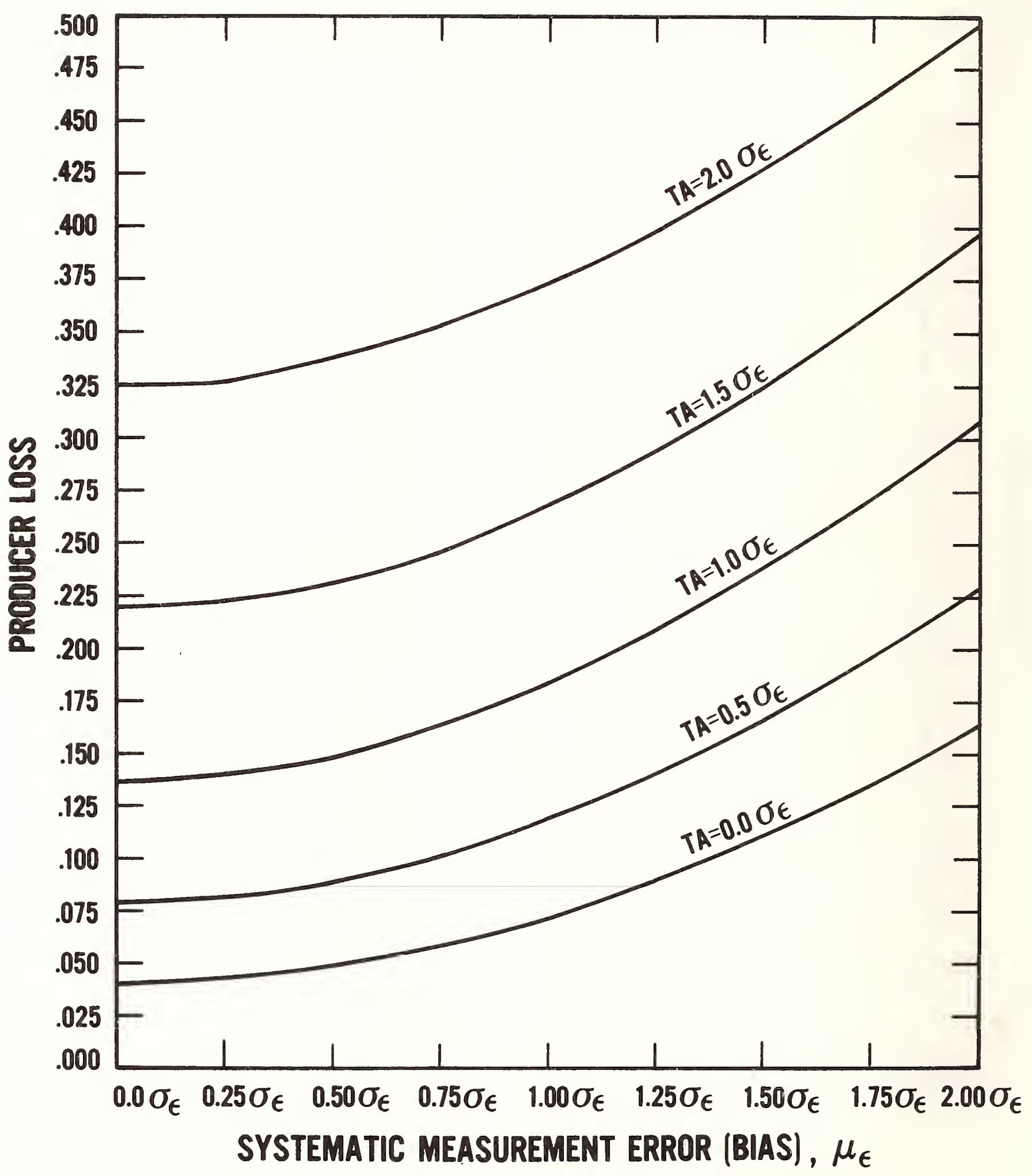

Figure B.4. Effect of Systematic Measurement Error on Producer's Loss $\left(\sigma_{\varepsilon}=0.5, \mu_{u}=0, \sigma_{u}=1, S_{U}=2, S_{L}=-2\right)$ 


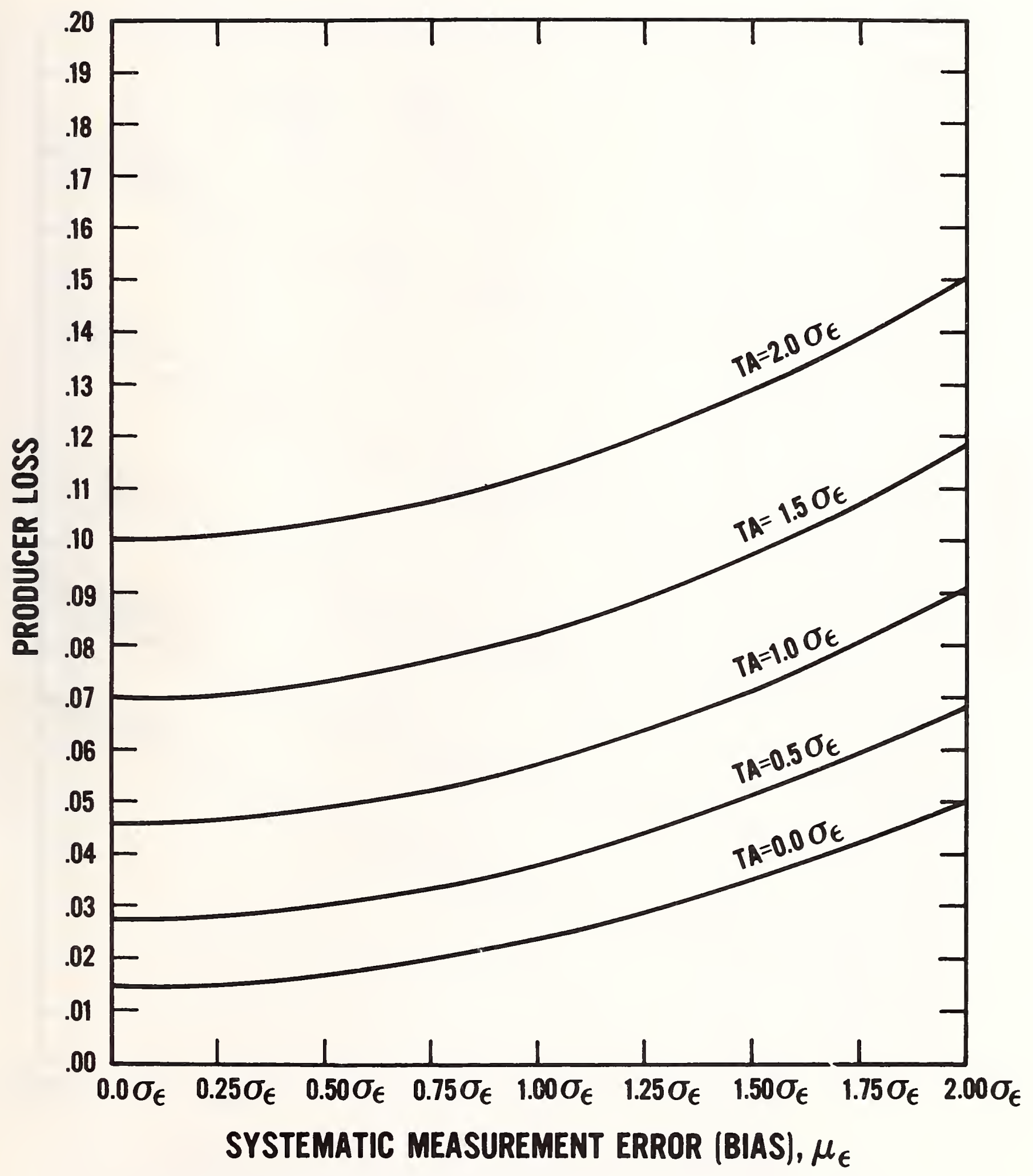

Figure B.5. Effect of Systematic Measurement Error on Producer's Loss $\left(\sigma_{\varepsilon}=0.25, \mu_{u}=0, \sigma_{u}=1, S_{U}=2, S_{L}=-2\right)$ 


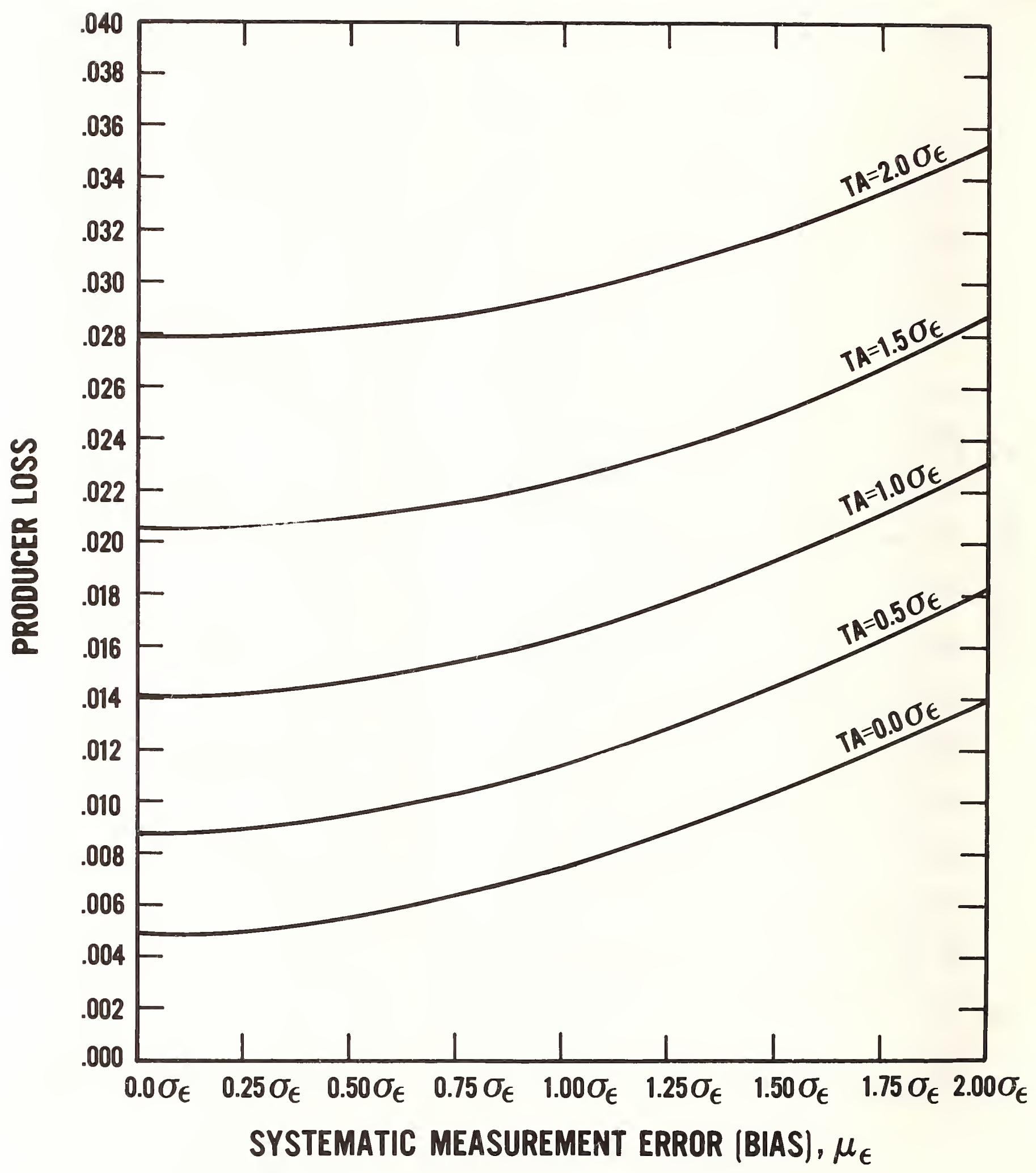

Figure B.6. Effect of Systematic Measurement Error on Producer's Loss $\left(\sigma_{\varepsilon}=0.1, \mu_{\mathrm{u}}=0, \sigma_{\mathrm{u}}=1, \mathrm{~S}_{\mathrm{U}}=2, \mathrm{~S}_{\mathrm{L}}=-2\right)$ 


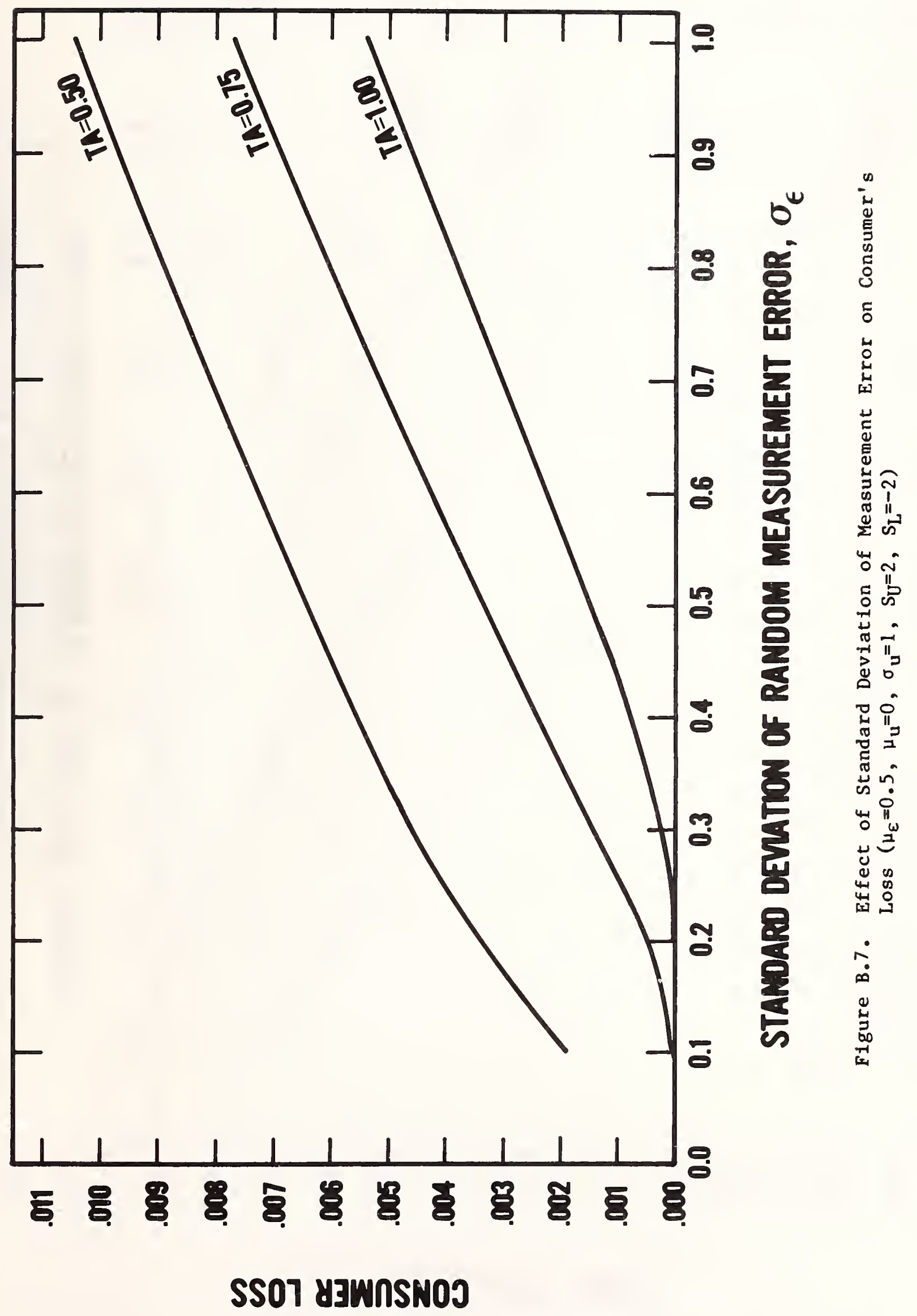




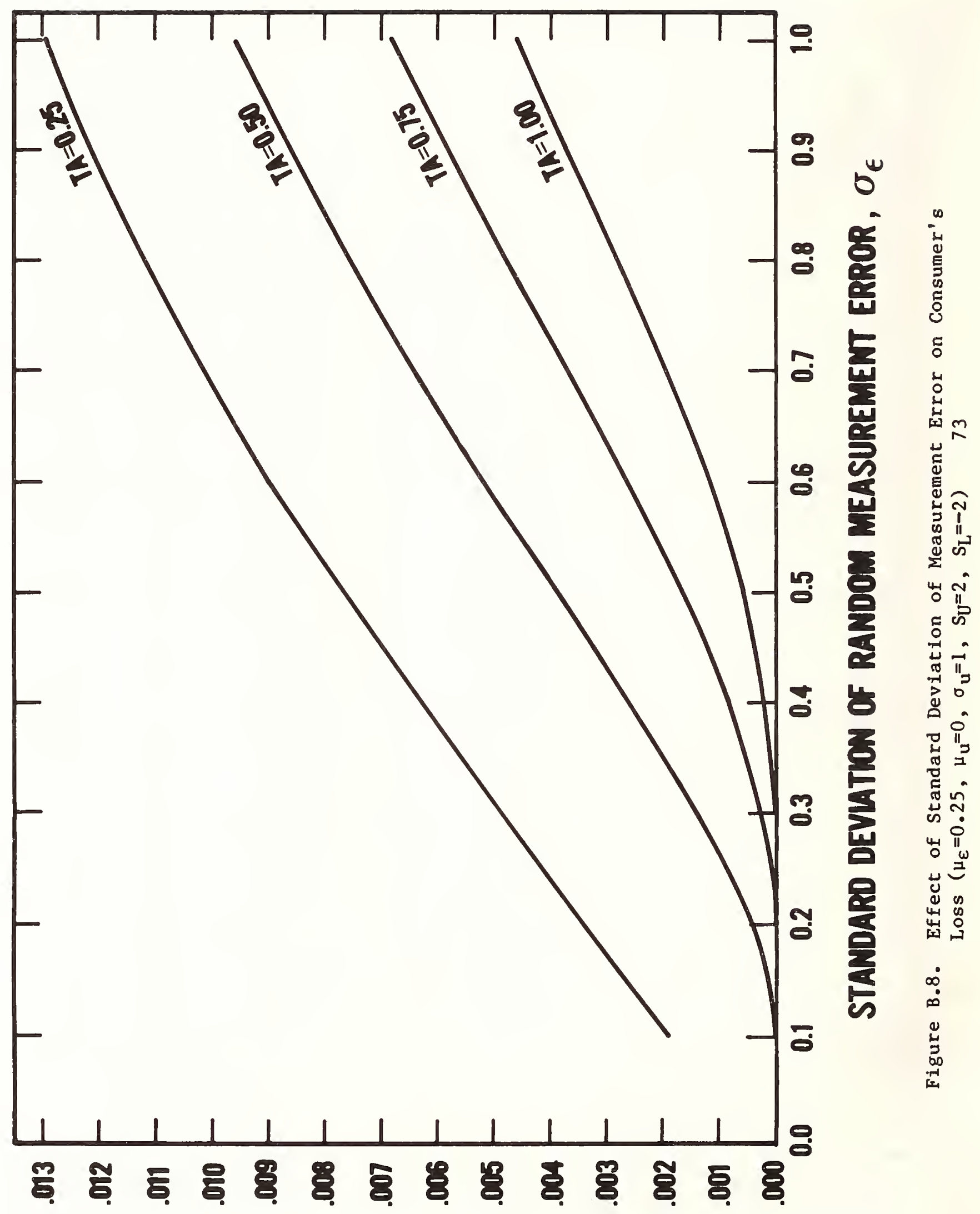

SSOT У3WกSNOJ 


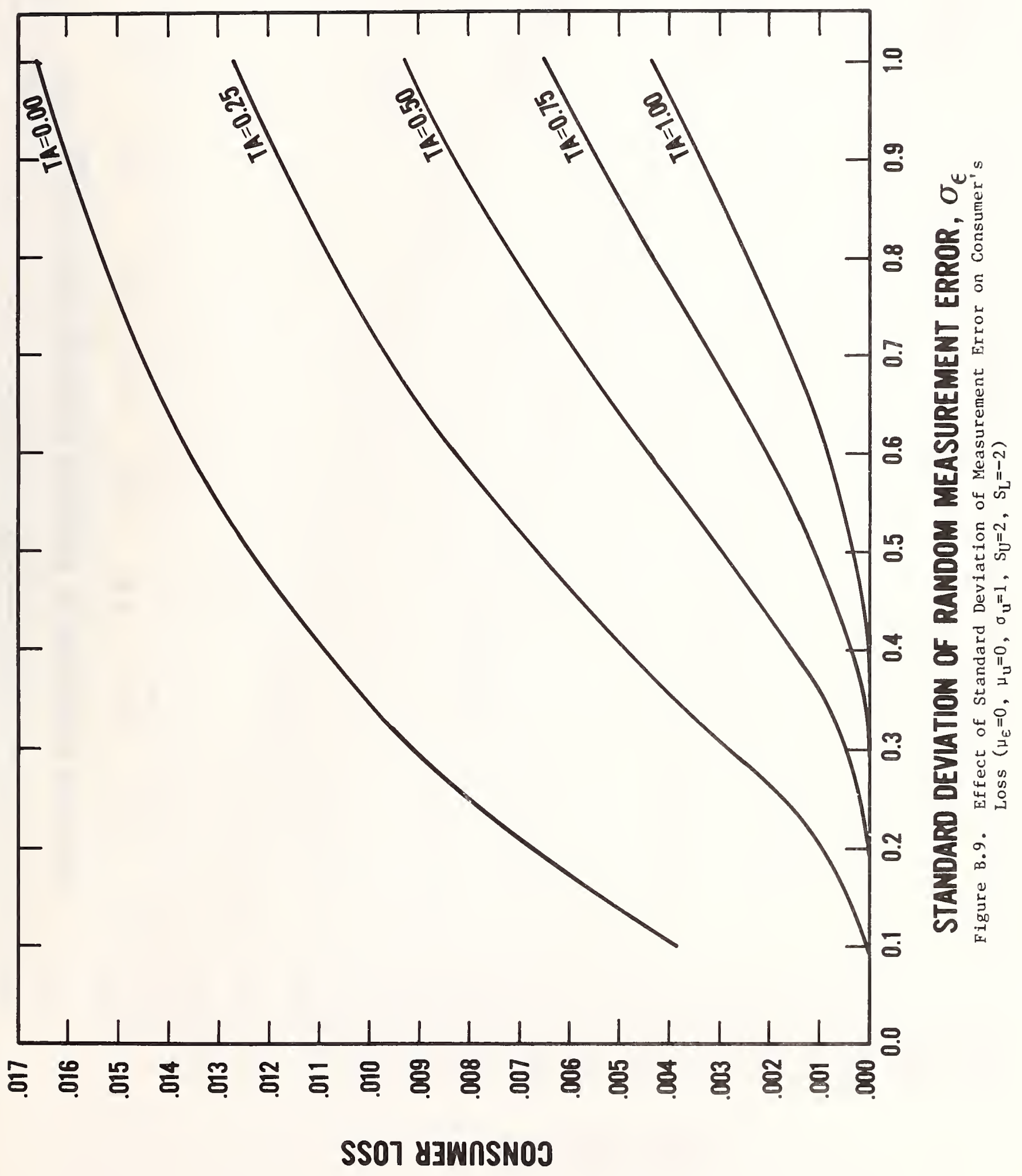




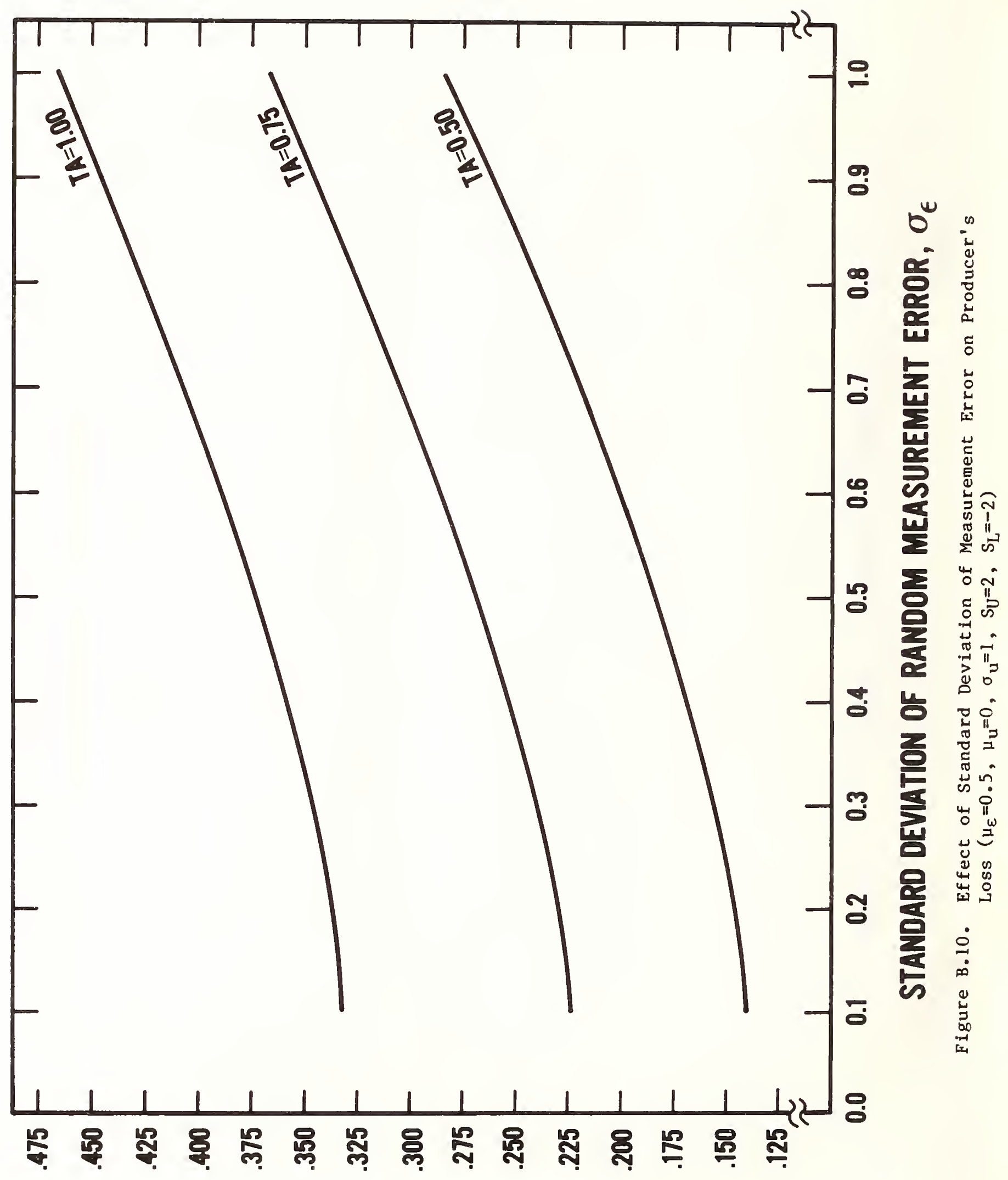

SS07 y3วno0yd 


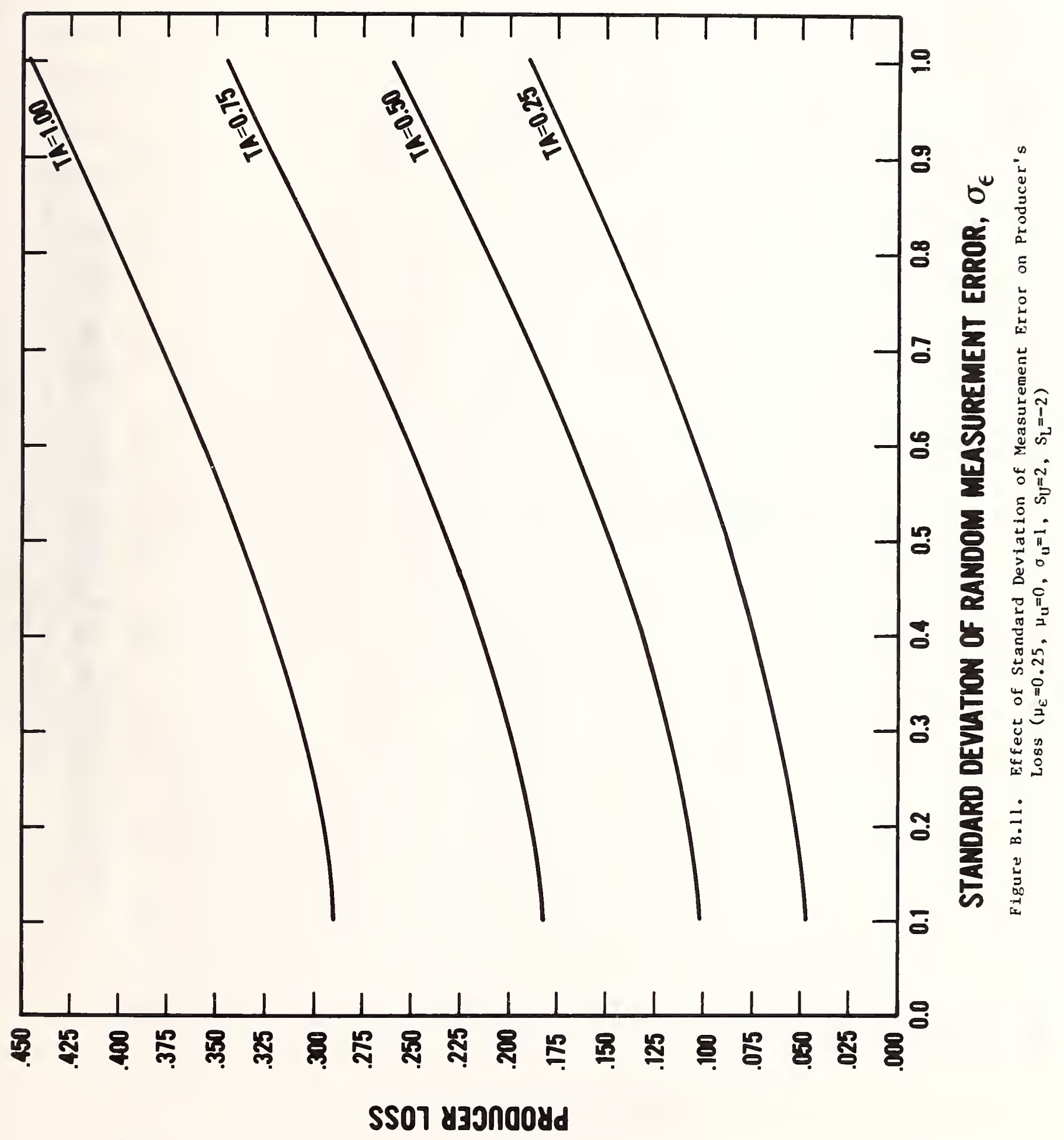




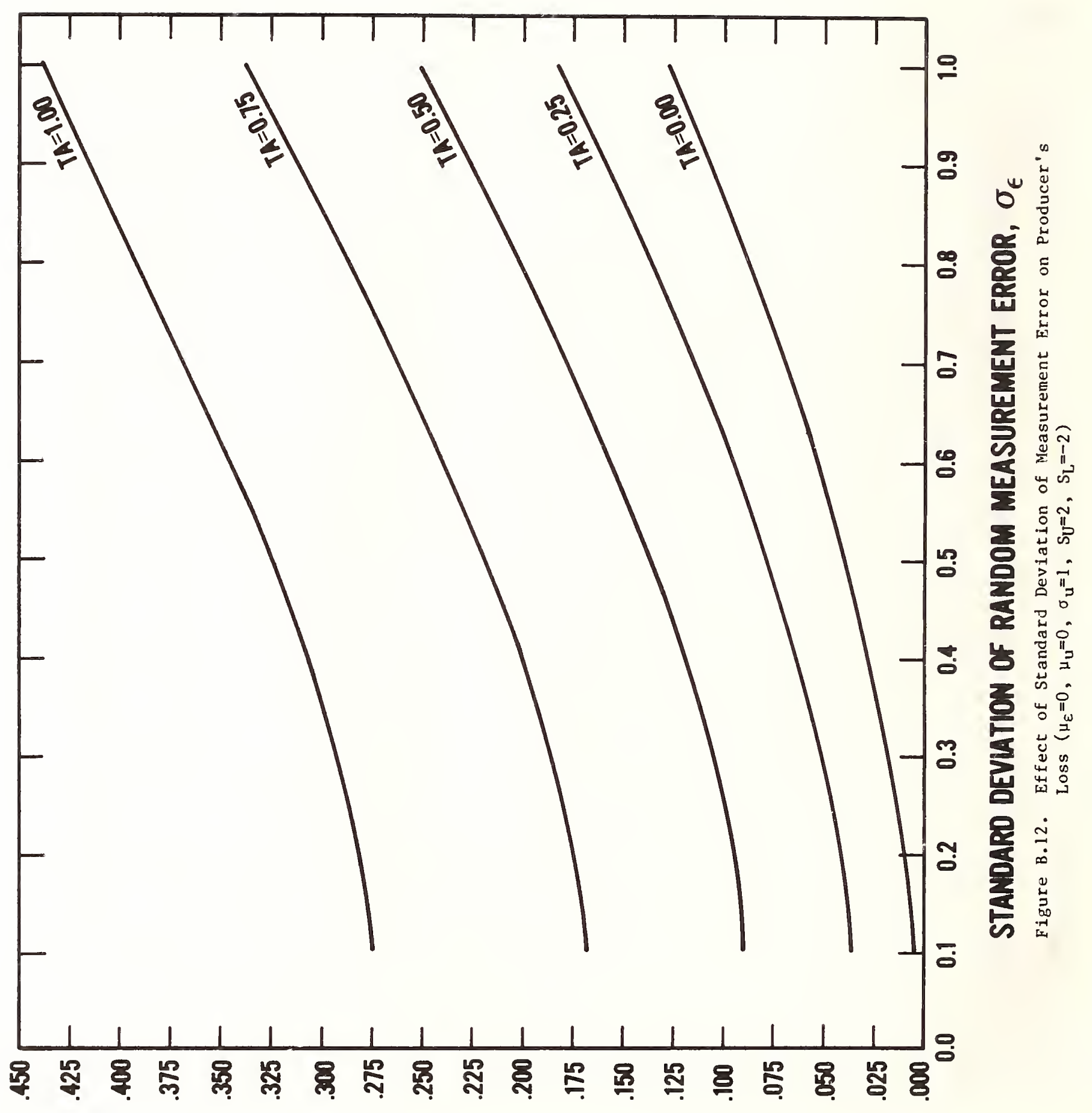

SSO7 y 3 JnoOyd 


\section{B.4 Illustrative Applications of the Figures}

In this subsection several examples are presented to illustrate how one can apply the figures to actual test situations. Suppose ATE is used in an electronics manufacturing plant to test a resistor that is a critical part of a calculator produced there. The resistor is known to have a normal performance distribution with mean 100.0 ohms and standard deviation $0.4 \mathrm{ohm}$. Historical records show that if the resistor performance is not within two standard deviations of the mean, then the calculator is very likely to fail during the one-year warranty period. On the basis of these records, the limits of acceptable performance for this resistor have been set at $\mu_{u} \pm 2 \sigma_{u}$ ohms. The plant quality assurance engineers also know that, for this range of resistance values and for the current system and frequency of calibration, the ATE readings are normally distributed with a typical systematic measurement error equal to $0.1 \mathrm{ohm}$ and standard deviation of the measurement error equal to $0.1 \mathrm{ohm}$. In the past, the engineers have always set the test tolerance at $0.1 \mathrm{ohm}$ to adjust for the measurement errors, but the resulting PL has been determined to be too high (i.e., the yield is too low because of unnecessary rejections). The plant managers want the engineers to find out what can be done to decrease PL and how CL will be affected as a result.

Case I: The first step in applying the figures to analyze this problem is to make sure the restrictions discussed in section B.2 are satisfied. This means adjusting the parameters as described In section B.2 and observing whether $S_{U}$ *

$=-S_{L} *=2$. The values given for the parameters were $\mu_{u}=100.0, \sigma_{u}=0.4, S_{U}$ $=\mu_{\mathrm{u}}+2 \sigma_{\mathrm{u}}=100.8, \quad \mathrm{~S}_{\mathrm{L}}=\mu_{\mathrm{u}}-2 \sigma_{\mathrm{u}}=99.2, \mu_{\varepsilon}=0.1, \sigma_{\varepsilon}=0.1$, and $\mathrm{TA}=0.1$. 
Standardizing $\mu_{u}, S_{U}$, and $S_{L}$, one obtains $\mu_{u^{*}}=(100.0-100.0) / 0.4=0, S_{U^{*}}=$ $(100.8-100.0) / 0.4=2.0$, and $\mathrm{S}_{\mathrm{L}}{ }^{*}=(99.2-100.0) / 0.4=-2.0$. Because $\mathrm{S}_{U^{*}}=$ $-\mathrm{S}_{\mathrm{L}} *=2$, the figures can be used to analyze this problem. Dividing the rest of the values by $\sigma_{u}$ to convert to the new scale yields $\sigma_{u}{ }^{*}=0.4 / 0.4=1.0$, $\mu_{\varepsilon}^{*}=0.1 / 0.4=0.25, \sigma_{\varepsilon}^{*}=0.1 / 0.4=0.25$, and $\mathrm{TA}^{*}=0.1 / 0.4=0.25$. Since both $\mu_{\varepsilon} *$ and $\sigma_{\varepsilon}$ equal 0.25 , the relevant plots are in figures B.2, B.5, B.8, and B.11. Reading from figures $\mathrm{B} .2$ and $\mathrm{B} .5$ we observe $\mathrm{CL}=0.0041$ and $\mathrm{PL}=$ 0.058 when $\mu_{\varepsilon}{ }^{*}=0.25\left(=1.0 \sigma_{\varepsilon}^{*}\right)$ and $T A^{*}=0.25\left(=1.0 \sigma_{\varepsilon}^{*}\right)$. Figures $\mathrm{B} .8$ and B.ll give the same values, as expected. Table B.1 summarizes the parameter values used and the resulting values of CL and PL for this base case and all remaining case illustrations in this section.

Case II: There are three variables that could possibly be changed: $\mu_{\varepsilon}, \sigma_{\varepsilon}$, and TA. Suppose improved or more frequent calibration of the ATE completely eliminated the systematic measurement error (i.e., $\mu_{\varepsilon}{ }^{*}=0$ ). From figures B.2 and B.5 it is seen that if $\mathrm{TA}$ is held constant, then CL will fall to 0.0018 and PL to 0.046 . Elimination of the systematic error causes a 0.0023 reduction in CL and a 0.012 reduction in PL. Thus, out of every lot of 10,000 resistors tested, 23 fewer bad UUTs will be incorrectly accepted and 120 fewer good UUTs will be unnecessarily rejected.

Case III: Now suppose that instead of improving ATE calibration, the company buys more precise ATE, which reduces $\sigma_{\varepsilon}$ to $0.04 \mathrm{ohm}$. Then $\sigma_{\varepsilon} *=0.1 （=$ $\left.0.1 \sigma_{u^{*}}\right)$ and it is seen from figures B.8 and B.11 that CL falls to 0.0019 and PL falls to 0.0475 . The drop in $\sigma_{\varepsilon}$ causes a 0.0022 reduction in CL and a 0.0105 reduction in PL. Thus, out of every lot of 10,000 resistors tested, 22 
Table B.l Parameter Values and Resulting Values of CL and PL for Case Examples.

\begin{tabular}{|c|c|c|c|c|c|c|c|c|c|}
\hline Case & $\begin{array}{c}\text { Parameter } \\
\text { Changed }\end{array}$ & $\begin{array}{l}\text { Paran } \\
\mu^{*} \varepsilon\end{array}$ & $\begin{array}{l}\text { ter } \\
\sigma_{\varepsilon}\end{array}$ & $\begin{array}{c}\text { Values } \\
\text { TA* }^{*}\end{array}$ & $\begin{array}{c}\text { Resulting } \\
\text { CL }\end{array}$ & $\begin{array}{c}\text { Values } \\
\text { PL }\end{array}$ & $\begin{array}{c}\text { Change } \\
\text { CL }\end{array}$ & from & $\begin{array}{c}\text { Base } \\
\text { PL }\end{array}$ \\
\hline I & Base & 0.25 & 0.25 & 0.250 & 0.0041 & 0.0580 & - & & - \\
\hline II & $\mu_{\varepsilon}$ & 0.00 & 0.25 & 0.250 & 0.0018 & 0.0460 & -0.0023 & & -0.0120 \\
\hline III & $\sigma_{\varepsilon}$ & 0.25 & 0.10 & 0.250 & 0.0019 & 0.0475 & -0.0022 & & -0.0105 \\
\hline IV & TA & 0.25 & 0.25 & 0.125 & 0.0070 & 0.0385 & +0.0029 & & -0.0195 \\
\hline V & $\mu_{\varepsilon}, \sigma_{\varepsilon}, \mathrm{TA}$ & 0.00 & 0.10 & 0.050 & 0.0019 & 0.0088 & -0.0022 & & -0.0492 \\
\hline VI & $\mu_{\varepsilon}, \mathrm{TA}$ & 0.00 & 0.25 & 0.125 & 0.0041 & 0.0276 & 0.0000 & & -0.0304 \\
\hline
\end{tabular}

a So that the figures can be applied to these case examples, each parameter value is given in units of the standard deviation of the UUT distribution. That is, as indicated by the asterisk, each has been divided by $\sigma_{u}=0.4 \mathrm{ohm}$. Note further that to interpret the figures correctly the values of $\mu_{\varepsilon}$ * and TA* must both be read in units of $\sigma_{\varepsilon} *$. 
fewer bad UUTs will now be incorrectly accepted and 105 fewer good UUTs will now be unnecessarily rejected. Clearly, in this case reducing $\mu_{\varepsilon}$ is more advantageous than reducing $\sigma_{\varepsilon}$. of course, the decision between improving calibration procedures to remove systematic error or purchasing more precise ATE would also have to take account of the costs of implementing each policy. Case IV: Suppose no changes are made in the measurement errors, but the test specifications are loosened by decreasing TA to $0.05 \mathrm{ohm}\left(\mathrm{TA}^{*}=0.125 \sigma_{\mathrm{u}}^{*}=\right.$ $\left.0.5 \sigma_{\varepsilon}^{*}\right)$. From figures B.2 and B.5, it is seen that this reduces PL to 0.0385 but increases CL to 0.0070 . The decrease in TA causes a 0.0195 reduction in PL and a 0.0029 increase in CL. The benefits of the large decrease in PL would have to be compared to the disadvantages of the increase in CL in order for the company to determine whether these changes in CL and PL, considered together, are indeed advantageous.

Case V: Changes in $\mu_{\varepsilon}, \sigma_{\varepsilon}$, and TA can also occur in combination. For instance, suppose the bias is eliminated, $\sigma_{\varepsilon}$ is reduced to 0.04 ohm $\left(\sigma_{\varepsilon}\right.$ * $=$ $\left.0.1 \sigma_{\mathrm{u}^{*}}\right)$, and TA is reduced to $0.02 \mathrm{ohm}\left(\mathrm{TA}^{*}=0.05 \sigma_{\mathrm{u}}^{*}=0.5 \sigma_{\varepsilon} *\right)$. Then it can be seen from the $\mathrm{TA}=0.5 \sigma_{\varepsilon}$ plots of figures $\mathrm{B} .3$ and $\mathrm{B.6}$ (where $\sigma_{\varepsilon} *=0.1$ ) that CL falls to 0.0019 and PL falls to 0.0088 . The combined changes in $\mu_{\varepsilon}$, $\sigma_{\varepsilon}$, and TA cause a 0.0022 decrease in CL and a 0.0492 decrease in PL from the original values. Thus, out of every lot of 10,000 resistors tested, 22 fewer bad UUTs will be incorrectly accepted and 492 fewer good UUTs will be unnecessarily rejected. The only combination of changes that cannot be analyzed with these figures is a decrease in $\sigma_{\varepsilon}$ combined with a decrease in TA to a value smaller than the assumed level of $\mu_{\varepsilon}$. This combination represents the situation discussed in section B.3. It should also be noted that not all possible values for the three variables are represented, so interpolation must sometimes be used to estimate the correct result. 
Case VI: Another application of these figures involves converting the effect of changes in $\mu_{\varepsilon}$ or $\sigma_{\varepsilon}$ into a single type of loss, holding the other loss value constant. This conversion would be useful when, for example, a purchase contract includes a specification limiting the allowable size of CL for a product, and the supplier wishes to hold CL at that limit while reducing PL as much as possible. It is also advantageous to convert a change in CL into an equivalent change in PL whenever it is difficult or impossible to establish a dollar value for a one-unit reduction in CL (e.g., in the case of health and safety hazards). To illustrate this application, consider again the resistor example. When the systematic measurement error was eliminated, it was determined that CL fell by 0.0023 and PL by 0.012 . But suppose the company management wished to keep CL at or near the original value of 0.0041 . From figure B.2 it is seen that this can be accomplished by lowering TA to 0.05 ohm $\left(\mathrm{TA}^{*}=0.125=0.5 \sigma_{\varepsilon}^{*}\right)$ when the systematic error is eliminated $\left(i . \mathrm{e}_{\bullet}, \mu_{\varepsilon}=0\right)$. It is seen from figure B.5 that PL falls to 0.0276 when the systematic error is eliminated and TA is reduced just enough to keep CL at its original level. of this total reduction in PL, 0.012 is directly due to the elimination of the systematic error, and the additional 0.0184 can be attributed to the effect of reducing $\mathrm{TA}$ enough to leave $\mathrm{CL}$ unchanged. In this way, the 0.0023 reduction in CL that is made possible by eliminating the systematic error has been converted to an equivalent 0.0184 reduction in PL.

One can apply the same method to make CL as low as possible while holding PL constant. Quality control policy might call for this type of conversion if the primary objective were to reduce reported failure rates. The extra 
reduction in CL would be accomplished by increasing $\mathrm{TA}$. In a similar manner, it is possible to achieve any desired ratio of CL to PL by changing TA. This possibility exists even when $\mu_{\varepsilon}$ and $\sigma_{\varepsilon}$ both remain unchanged. The figures presented here may require interpolation of TA in order to estimate the effects on CL and PL of changing TA. More accurate results can be obtained by using the program BINORMAL.CL-PL, described in appendix $A$, and using the sensitivity analysis capability to vary TA until acceptably accurate results are obtained. The ability to vary TA to achieve a desired ratio of CL and PL is useful in establishing the economically optimal trade-off between CL and PL, provided data are available on the relative cost of each unit of CL and PL. 
NBS.114A (REV. 2.8C)

U.S. DEPT. OF COMM.

1. PUBLICATION OR REPORT NO.

BIBLIOGRAPHIC DATA

SHEET (See in struction s)

NBS SP 673

2. Performıng Organ. Report No. 3. Publication Date

4. TITLE AND SUBTITLE

Economic Model of Calibration Improvements for Automatic Test Equipment

\section{AUTHOR(S)}

Stephen F. Weber and Anne P. Hillstrom

6. PERFORMING ORGANIZATION (If joint or other thon NBS, see in structions)

7. Contract/Grant No.

NATIONAL BUREAU OF STANDARDS

DEPARTMENT OF COMMERCE

WASHINGTON, D.C. 20234

April 1984

SPONSORING ORGANIZATION NAME AND COMPLETF ADDRESS (Street, City, stote, ZIP)

Center for Electronics and Electrical Engineering

Center for Applied Mathematics

National Bureau of Standards

Washington, DC 20234

10. SUPPLEMENTARY NOTES

Library of Congress Catalog Card Number: 84-601027

Document describes a computer program; SF-185, FIPS Software Summary, is attached.

11. ABSTRACT (A 200-word or less foctual summory of mast significant information. If document includes o significant bibliogrophy or literoture survey, mention it here)

This paper presents a model for measuring the benefits of improved accuracy in test equipment. The model permits calculation of the probability of accepting a unit under test (UUT) that is out of specifications (i.e., Consumer's Loss) and the probability of rejecting a UUT that is within specifications (i.e., Producer's Loss) for alternative levels of test equipment accuracy. Accuracy is defined in terms of both the systematic and the random measurement error of the equipment. Other parameters that are taken into account by the model are the mean and variance of the UUT attribute of interest, the performance specifications of the UUT, and the test specifications which define acceptance and rejection in terms of test measurement results. A discussion of the economic consequences of Consumer's Loss and Producer's Loss is included. The model may be used to optimize both procurement policy for new test equipment as well as maintenance and calibration policy for existing test equipment.

12. KEY WORDS (Six to twelve entries: alphobetical order; capitalize only proper names; and separate key words by semicolons) accuracy; automatic test equipment; calibration; Consumer's Loss; economics; error analysis; measurement; Producer's Loss; quality assurance; random error; systematic crror; testing.

13. AVAILABILITY

[X] Unlimited

$\square$ For Official Distribution. Do Not Release to NTIS

Xrder From Superintendent of Documents, U.S. Government Printing Office, Washington, D.C. 20402.

14. NO. OF PRINTED PAGES 94

15. Price

Order From National Technical Information Service (NTIS), Springfield, VA. 2216I 


\section{NBS TECHNICAL PUBLICATIONS}

\section{PERIODICALS}

JOURNAL OF RESEARCH-The Journal of Research of the National Bureau of Standards reports NBS research and development in those disciplines of the physical and engineering sciences in which the Bureau is active. These include physics, chemistry, engineering, mathematics, and computer sciences. Papers cover a broad range of subjects, with major emphasis on measurement methodology and the basic technology underlying standardization. Also included from time to time are survey articles on topics closely related to the Bureau's technical and scientific programs. As a special service to subscribers each issue contains complete citations to all recent Bureau publications in both NBS and nonNBS media. Issued six times a year. Annual subscription: domestic $\$ 18$; foreign $\$ 22.50$. Single copy, $\$ 5.50$ domestic; $\$ 6.90$ foreign.

\section{NONPERIODICALS}

Monographs-Major contributions to the technical literature on various subjects related to the Bureau's scientific and technical activities.

Handbooks-Recommended codes of engineering and industrial practice (including safety codes) developed in cosperation with interested industries, professional organizations, and regulatory bodies.

Special Publications-Include proceedings of conferences spon. sored by NBS, NBS annual reports, and other special publications appropriate to this grouping such as wall charts, pocket cards, and bibliographies.

Applied Mathematics Series-Mathematical tables, manuals, and studies of special interest to physicists, engineers, chemists, biologists, mathematicians, computer programmers, and others engaged in scientific and technical work.

National Standard Reference Data Series--Provides quantitative data on the physical and chemical properties of materials, compiled from the world's literature and critically evaluated. Developed under a worldwide program coordinated by NBS under the authority of the National Standard Data Act (Public Law 90-396).

NOTE: The principal publication outlet for the foregoing data is the Journal of Physical and Chemical Reference Data (JPCRD) published quarterly for NBS by the American Chemical Society (ACS) and the American Institute of Physics (AIP). Subscriptions, reprints, and supplements available from ACS, 1155 Sixteenth St, NW, Washington, DC 20056.
Building Science Series-Disseminates technical irformation developed at the Bureau on building materials, components, systems, and whole structures. The series presents research results, test methods, and performance criteria related to the structural and environmental functions and the durability and safety characteristics of building elements and systems.

Technical Notes-Studies or reports which are complete in themselves but restrictive in their treatment of a subject. Analogous to monographs but not so comprehensive in scope or definitive in treatment of the subject area. Often serve as a vehicle for final reports of work performed at NBS under the sponsorship of other government agencies

Voluntary Product Standards-Developed under procedures published by the Department of Commerce in Part 10, Title 15, of the Code of Federal Regulations. The standards establish nationally recognized requirements for products, and provide all concerned interests with a basis for common understanding of the characteristics of the products. NBS administers this program as a supplement to the activities of the private sector standardizing organizations.

Consumer Information Series-Practical information, based on NBS research and experience, covering areas of interest to the consumer. Easily understandable language and illustrations provide useful background knowledge for shopping in today's technological marketplace.

Order the above NBS publications from: Superintendent of Documents. Government Printing Office, Washington. DC 20402.

Order the following NBS publications-FIPS and NBSIR's-from the National Technical Information Service. Springfield, VA 22161.

Federal Information Processing Standards Publications (FIPS PUB)-Publications in this series collectively constitute the Federal Information Processing Standards Register. The Register serves as the official source of information in the Federal Government regarding standards issued by NBS pursuant to the Federal Property and Administrative Services Act of 1949 as amended. Public Law 89-306 (79 Stat. 1127), and as implemented by Executive Order 11717 (38 FR 12315, dated May 11, 1973) and Part 6 of Title 15 CFR (Code of Federal Regulations).

NBS Interagency Reports (NBSIR) - A special series of interim or final reports on work performed by NBS for outside sponsors (both government and non-government). In general, initial distribution is handled by the sponsor; public distribution is by the National Technical Information Service, Springfield, VA 22161. in paper copy or microfiche form. 
U.S. Department of Commerce

National Bureau of Standards

Washington. D.C. 20234

Official Business

Penalty for Private Use $\$ 300$ 